\title{
Recovery of Polyhydroxyalkanoates From Single and Mixed Microbial Cultures: A Review
}

\author{
Giorgia Pagliano ${ }^{1}$, Paola Galletti ${ }^{1,2}$, Chiara Samorì ${ }^{1,2 *}$, Agnese Zaghini ${ }^{1}$ and \\ Cristian Torri1,2*
}

${ }^{1}$ Department of Chemistry "Giacomo Ciamician", University of Bologna, Ravenna, Italy, ${ }^{2}$ CIRI-Fonti Rinnovabili, Ambiente, Mare ed Energia, Ravenna, Italy

\section{OPEN ACCESS}

Edited by:

Paulo Costa Lemos, NOVA School of Science and Technology, Portugal

Reviewed by: Francesco Valentino, Sapienza University of Rome, Italy Maciej Guzik

Jerzy Haber Institute of Catalysis and Surface Chemistry, Polish Academy of Sciences, Poland

*Correspondence:

Chiara Samori chiara.samori3@unibo.it Cristian Torri

cristian.torri@unibo.it

Specialty section:

This article was submitted to

Bioprocess Engineering,

a section of the journal

Frontiers in Bioengineering and

Biotechnology

Received: 30 October 2020

Accepted: 18 January 2021

Published: 10 February 2021

Citation:

Pagliano G, Galletti P, Samori C, Zaghini A and Torri C (2021) Recovery of Polyhydroxyalkanoates From Single and Mixed Microbial Cultures:

A Review.

Front. Bioeng. Biotechnol. 9:624021. doi: 10.3389/fbioe.2021.624021
An overview of the main polyhydroxyalkanoates (PHA) recovery methods is here reported, by considering the kind of PHA-producing bacteria (single bacterial strains or mixed microbial cultures) and the chemico-physical characteristics of the extracted polymer (molecular weight and polydispersity index). Several recovery approaches are presented and categorized in two main strategies: PHA recovery with solvents (halogenated solvents, alkanes, alcohols, esters, carbonates and ketones) and PHA recovery by cellular lysis (with oxidants, acid and alkaline compounds, surfactants and enzymes). Comparative evaluations based on the recovery, purity and molecular weight of the recovered polymers as well as on the potential sustainability of the different approaches are here presented.

Keywords: polyhydroxyalkanoates, extraction methods, green solvents, mixed microbial cultures, single microbial strains, surfactants, cell lysis

\section{INTRODUCTION}

Polyhydroxyalkanoates are a family of bio-polyesters constituted by 3-hydroxy acid monomers (e.g., mainly 3-hydroxybutyric acid copolymerized with longer monomers as 3-hydroxyvaleric acid) and produced by bacterial fermentation as intracellular carbon and energy storage. Despite their potential in the scenario of fossil plastic replacement due to thermo-physical properties like petrochemically-derived plastics, PHAs are currently more costly than standard petrochemical plastics (1.18-6.12 $€ / \mathrm{kg} v s .<1 € / \mathrm{kg}$, Saavedra del Oso et al., 2020) and cover niche-market highvalue applications (Samorì et al., 2015b; Valentino et al., 2017). The combination of two factors determines the current PHA high production cost: upstream costs and downstream costs. A huge effort has been devoted at reducing the upstream costs by investigating both the suitability of cheap raw materials as feed for PHA-producing bacteria and the suitability of alternative microbial consortia for fermenting unusual feedstock; to this purpose different kinds of wastewater streams (food waste, sugar cane molasses, olive mill wastewater, waste activated sludge, paper mill wastewater, cheese whey, Mannina et al., 2019) have been used for feeding mixed microbial cultures (MMC) that proved to have wider metabolic potential than single strains and to be cheaper in terms of operative costs (Dias et al., 2006; Serafim et al., 2008a; Mannina et al., 2020).

On the other hand, downstream processes (PHA recovery and purification) are among the least investigated aspects of the whole PHA production chain but the most impacting ones in terms of economic weight (Jiang et al., 2015; Koller et al., 2017; Saavedra del Oso et al., 2020). High energy consumption is intrinsic in the overall PHA production life cycle, especially during the PHA downstream processing, and this aspect is 
clearly highlighted by life cycle assessment (LCA) studies that compare PHA and fossil plastics, having the firsts a higher carbon footprint despite being biobased and biodegradable (Saavedra del Oso et al., 2020).

The use of (i) appropriate organic solvents to extract PHA granules from inside the bacterial cells, or (ii) additives/chemical agents to disrupt cellular matrix (dissolution of non-PHA cell mass, NPCM) and releasing intracellular PHA, are the two approaches of choice in the downstream phase, often coupled with pretreatments (e.g., with an oxidant, or thermally assisted) to enhance the permeability of cellular membranes. Both are characterized by peculiar advantages and undeniable drawbacks (Samorì et al., 2015b): PHA-friendly solvents, especially the chlorinated ones, provide high extraction yields and high polymer quality (high molecular weight and low impurities) but they are often hazardous for the environment and for the operators. Moreover, the solvent-based processes require relevant operational costs due to the high quantity of solvents that has to be used (up to 20-folds the PHA-rich biomass) and the high amount of energy employed for solvent evaporation and partial/total water removal from bacterial biomass to improve the contact between hydrophobic solvents and PHA granules stored inside the cells (Koller et al., 2013; Madkour et al., 2013). The additives for achieving cellular lysis (enzymes, surfactants, oxidants, alkali) can be directly applied to microbial cultures, by-passing the drying of the biomass, but they can affect the characteristics of the extracted polymer, leading to PHA degradation and reduction of molecular weight (Kosseva and Rusbandi, 2018; Mannina et al., 2020). Moreover, these agents are often non-recyclable and consequently, the remaining aqueous solutions are wasted and must be treated.

The search for more sustainable alternatives for PHA extraction that could decrease both the environmental and economic impact of the current approaches has been investigated in the last years: linear and cyclic carbonates (Fiorese et al., 2009; Samorì et al., 2015a,b), ethyl acetate (Riedel et al., 2013), methyl isobutyl ketone (Riedel et al., 2013), ionic liquids, and supercritical fluids (Hampson and Ashby, 1999) are some examples of solvents used in the first approach, whereas recyclable surfactants are among the alternatives developed within the second approach (Samorì et al., 2015b; Mannina et al., 2019). In this framework it has also emerged that PHA-accumulating bacteria do not behave in the same way toward organic solvents or chemical additives: MMCs, cheaper in terms of upstream than single strains, seem more resistant to cell hydrolysis probably because of strong and complex extracellular biomass matrix that contains the PHA accumulating cells (Patel et al., 2009; Samorì et al., 2015b). This aspect poses a further complication in making the PHA-production process economically competitive with respect to fossil-based plastics and other bioplastics already on the market.

In this review, an overview of the various downstream approaches applied to single strains and MMCs for recovering PHAs is presented. These methods have been divided into two main categories: recovery with solvents and recovery by cellular lysis. A comparative assessment among them was shown by considering the recovery, purity, molecular weight, and polydispersity index of the recovered polymer. The last three properties, in fact, are among the most important parameters for determining the applicability of each specific PHA in the various fields; if PHA purity is strictly correlated to human-related applications (e.g., biomedical ones), PHA molecular weight, and polydispersity index are detrimental for PHA processability. In fact, mechanical properties of polymers (e.g., the tensile strength) are affected by their molar mass; molecular weight values above $0.5 \mathrm{MDa}$ and polydispersity index below 3 are usually considered acceptable thresholds for these thermoplastic polymers, being typical of quite homogeneous chain lengths that can be processed through injection molding techniques without any compromising reduction in the total polymer length (Fiorese et al., 2009). Some studies have reported for example that a molecular weight below $0.1 \mathrm{MDa}$ causes severe deterioration of the mechanical properties for $\mathrm{P}(\mathrm{HB}-\mathrm{HV})$ (Burniol-Figols et al., 2020).

It is worth mentioning that PHAs are currently used as a chemically-extracted bulk material. However, it has been demonstrated that the extraction process, independently by being a solvent-based or a cellular lysis approach, has a crucial role in determining the properties of the extracted PHA, both in terms of crystallinity and purity, altering the original morphology of PHA granules. In fact, storage PHB (high molecular weight polymer with $>10^{3} 3$-HB units) and related PHA are accumulated intracellularly in the form of granules whose surface is surrounded by a considerable number of proteins (about $1.9 \mathrm{wt} \%$ ), much more than those essential for PHA synthesis (Jendrossek and Pfeiffer, 2014). These structural, biosynthetic, catabolic, and even regulatory proteins, embedded in lipid monolayer (Merrick and Doudoroff, 1964; Mayer and Hoppert, 1997), create a surface layer around the polymer core (Jendrossek and Pfeiffer, 2014), and this complex structure have suggested a wider function of $\mathrm{PHB} / \mathrm{PHA}$ granules (thus named "carbonosomes," Jendrossek, 2009) a part being an energy and carbon storage. When PHA granules are exposed to (bio)chemical (e.g., extraction with alkaline compounds, solvents, enzymes) or physical processes (freezing, pelleting by centrifugation), they rapidly undergo denaturation processes (Merrick and Doudoroff, 1964) and become more crystalline (typical degree of crystallinity 50-60\%, Jendrossek, 2007) than the native PHB granules (in which the polymer chains are in an amorphous state due to a certain amount of water that acts as a plasticizer and prevents crystallization, Grage et al., 2009); moreover, the extracted PHA granules seem to retain the proteinaceous surface layer typical of the native PHB granules (Kuchta et al., 2007), meaning that a $100 \%$ purity of the granules is hard to be achieved. To avoid denaturation during the isolation process, it has been claimed that native PHA granules must be recovered by using mechanic (e.g., French Press) or enzymatic cell lysis followed by density gradient centrifugation; in this way, the particular spherical structure of native PHA granules and their shell-core composition could be maintained and thus exploitable in a broad range of applications in biotechnology and medicine, from protein purification to drug delivery (Grage et al., 2009). Although this approach could drastically increase the applicability of PHA in unexplored fields due to the extraction of 
such peculiar PHB-carbonosomes, this review will mainly focus on PHA as low-medium cost bulk material, potentially capable of playing a role in the future bioplastic scenario.

\section{PHA EXTRACTION: PROCESS STEPS AND ISSUES}

\section{Methodologies to Determine the PHB/PHA Content Inside Microbial Cells, Recovery, Purity, Molecular Weight and Polydispersity Index}

This review aims at comparing various extraction approaches by considering four different parameters: polymer recovery, purity, molecular weight, and polydispersity index of the recovered polymer. Therefore, their definitions and the most common methodologies to quantify all of them have been initially reported in this section.

\section{PHA Recovery (\%)}

The recovery of PHA is directly correlated to PHA extraction yield, purity of the extracted PHA, and initial PHA content inside microbial cells as follows:

$$
\left[\mathrm{PHA} \text { recovery }(\%)=\frac{\mathrm{PHA} \text { yield }(\mathrm{wt} \%)^{*} \mathrm{PHA} \text { purity }(\%)}{\mathrm{PHA} \text { amount in the microbial cells }(\mathrm{wt} \%)}\right]
$$

\section{PHA Yield (wt\%)}

The yield of the extracted PHA is usually calculated gravimetrically on a microbial biomass weight basis (wt\%). The weight of the recovered polymer can be achieved after: (i) evaporating the solvent used for the extraction until reaching a constant PHA weight, (ii) adding an anti-solvent to the solvent used for the extraction (e.g., EtOH added to chlorinated compounds), (iii) lysing the microbial cells. If an anti-solvent or a cell-lysis approach is used, the PHA granules are recovered by centrifugation, washed with the anti-solvent or $\mathrm{H}_{2} \mathrm{O}$, and then dried until reaching a constant weight.

\section{PHA Purity (\%)}

The purity of the extracted PHA can be determined by various approaches that fall into two main categories:

(i) methods to quantify the impurities associated with the extracted polymer, typically oriented toward specific classes of bacterial contaminants like proteins, endotoxins, or lipids:

- Proteins (about 1.9 wt\%) are strictly associated to PHA granules, forming the so-called "carbonosomes" structure (Jendrossek, 2009) that is recalcitrant independently by the recovery approach (solvents or lytic agents); this residual content is directly quantifiable through the Lowry method (Lowry et al., 1951) or indirectly estimable through elemental analysis from the $\mathrm{N}$ amount of the sample (assuming that proteins have a mean nitrogen content of about $6 \%$, Sosulski and Imafidon, 1990). A possible strategy to reduce protein residual content is the application of proteases after the extraction process.

- Pyrogenic lipopolysaccharides (LPS) form part of the cell wall of Gram-negative bacteria and are released into the environment when the membrane of these bacteria is broken; LPS represent the so-called "endotoxins" and are associated to the extracted PHA independently by the recovery approach; however, it has been proved that solvents extraction (e.g., with chloroform) gives lower endotoxin level (three orders of magnitude) than celllysis (Lee et al., 1999). LPS residual content can be semiquantitatively determined by ad hoc tests like the Limulus Amebocyte Lysate (LAL) test, whose principle is based on the gelation process that occurs from the coagulation of the proteins caused by the presence of endotoxins (Lee et al., 1999). Possible strategies to reduce LPS residual content are the application of alkaline or oxidizing posttreatments to the extracted PHA (however causing the hydrolysis of PHA itself), repeated polymer dissolutionprecipitation cycles (however causing a massive solvents consumption), or filtration through charcoal (however causing a considerable loss of PHA, Wampfler et al., 2010a; Koller et al., 2013).

- Lipids are usually found associated with extracted PHA if solvent approaches are used; this occurs because of the "like dissolves like" rule of thumb, according to which non-polar solvents used to solubilize PHA are also capable of dissolve non-polar solutes like lipids. Lipidic residual content is directly quantifiable through various techniques like thin-layer chromatography (TLC), gas chromatography (GC), liquid chromatography (LC), enzyme-linked immunosorbent assays (ELISA), nuclear magnetic resonance (NMR), and mass spectrometry (MS) (Li et al., 2014). Due to the similar chemical nature of lipids and PHA, post-treatment purification is quite hard; however, it can be useful to pretreat (degrease) the microbial biomass with solvents like methanol, ethanol, acetone, or supercritical $\mathrm{CO}_{2}\left(\mathrm{scCO}_{2}\right)$ that are scarcely suitable for PHA but not for lipids, weakening at the same time the cell envelops (Koller et al., 2013).

(ii) methods to quantify the PHA material in the mass recovered through solvent extraction or cell-lysis like methanolysis coupled to chromatographic analysis or thermogravimetric (TGA) analysis (see below). The main issue of the methods that calculate the purity level from the PHA content in the recovered material is that, even with a minor relative standard deviation (RSD) of the replicas, the absolute error becomes intrinsically comparable to the distance between measured purity and 100\%. Gas chromatographic analysis, for example, typically brings 1$2 \%$ RSD due to imprecisions in weighing or dilution, thus more than 4-6 replicas (of a perfectly homogenous material) are needed to reduce the $95 \%$ confidence range of the data to $1 \%$. If the confidence range is $1 \%, 99 \%$ purity can be investigated. 
Given that pretreatment or derivatization procedures usually add a significant variability to the methods (RSD can exceed 5\%) the number of replicas required to prove higher purities ( $>99 \%$ ) becomes unfeasible. TGA analysis is characterized by higher precision $(\mathrm{RSD}<1 \%$ ), therefore it can be easily used (with a few replicas) to assess purity levels until $99 \%$. Nonetheless, given the limitations highlighted above, all known methods that quantify the PHA material in the mass recovered cannot be used for a reliable determination of purities higher than $99 \%$. When the interest is in determining a minimal amount of impurities, which is the case of higher purity investigation, direct quantification of impurities is markedly more efficient.

\section{PHA Amount in Microbial Cells (wt\%)}

Several methods have been suggested in the last 50 years to quantify the PHA amount inside microbial cells and their monomeric composition (e.g., chromatographic, turbidimetric, spectrophotometric approaches) (Williamson and Wilkinson, 1958; Ward and Dawes, 1973; Braunegg et al., 1978; Gorenflo et al., 1999). Among them, methanolysis coupled to chromatographic analysis is considered one of the most reliable and accurate methods (Braunegg et al., 1978). It basically consists of a transesterification reaction (depolymerization) in methanol $\left(>3 \mathrm{~h}\right.$ at $\left.100^{\circ} \mathrm{C}\right)$ catalyzed by $\mathrm{H}_{2} \mathrm{SO}_{4}$ to give the methylesters of PHA monomers (e.g., methyl 3-hydroxybutyrate from $\mathrm{PHB}$ ), that are extracted by chlorinated solvents (e.g., dichloromethane or chloroform) and then analyzed by gas chromatography. The quantification of the methylesters by using an internal standard or a calibration curve gives the PHA content on a bacterial biomass weight basis. Despite being the method of choice in the field of PHA quantification, this procedure is far from being considered "green" (according to the modern concept of Green Analytical Chemistry, Gałuszka et al., 2013) since it is based on a lengthy transesterification reaction that needs the use of a considerable amount of harsh and harmful reagents (e.g., $\mathrm{H}_{2} \mathrm{SO}_{4}$ and chloroform) for forming and isolating the analytes. The need for fast routine solvent-less methods to reduce sample pretreatment, speed up the analysis and decrease the overall costs has brought toward the birth of a new generation of quantitative analysis based on the exploitation of the thermal properties of PHA (Morikawa and Marchessault, 1981; Hahn and Chang, 1995; Aoyagia et al., 2002; Li et al., 2003). PHA is thermally unstable above $180^{\circ} \mathrm{C}$ and this behavior can be exploited to depolymerize PHA and give specific analytes (namely 2 -alkenoic acids) that can be used as markers for quantifying intracellular PHA and their monomeric composition. Thermal treatments like thermogravimetric analysis (TGA, Hahn and Chang, 1995), pyrolysis (Morikawa and Marchessault, 1981; Torri et al., 2014), or low-temperature thermolysis (Abbondanzi et al., 2017) have been exploited to this purpose, representing a faster and equally reliable alternative to conventional methanolysis-chromatography approach.

\section{Molecular Weight and Polydispersity Index}

Number and average molecular weight, as well as polydispersity index (a proxy of the distribution of the molecular weight and, thus, the heterogeneity of the polymer), are usually determined in chloroform solution by a comparative technique like gel permeation chromatography (GPC) using a single concentration detector (typically refractive index, RI). Care should be taken since some PHA tend to form gels in chloroform (as in some other "super-solvents" like $\gamma$-valerolactone, Samorì et al., 2016), hence their concentration should be kept below the gel point.

\section{General Process Steps}

The main steps involved in the two strategies (recovery with solvents and recovery by cellular lysis), as well as the most relevant technical/environmental issues that should be particularly considered (in red) are highlighted in Figures 1, 2.

Solvent extraction of PHA from dry or wet microbial biomass (e.g., microbial slurry in which the content of biomass could be around $10-20 \mathrm{wt} \%$ ) typically includes the following steps:

(1) Putting in contact biomass and admixing it with solvent; this is a relatively low energy consumption operation.

(2) Heating up the mixture to the desired extraction temperature. Such a step involves sensible heat that can be reliably recovered (more than 80\%) through counter-current heat exchangers. The order of magnitude of the energy consumption for reaching the extraction temperature could be calculated from the heat capacities of the solvent and microbial biomass. Since the extraction is typically performed at a temperature lower than the PHA decomposition temperature $\left(<200^{\circ} \mathrm{C}\right)$, the heat capacity of solvents/biomass ranges between $1-2 \mathrm{~kJ} \mathrm{~kg}^{-1} \mathrm{~K}^{-1}$ and the heat capacity of water (eventually present if a microbial slurry with $10-20 \mathrm{wt} \%$ of biomass is subjected to the extraction) is equal to $4.2 \mathrm{~kJ} \mathrm{~kg}^{-1} \mathrm{~K}^{-1}$. The required energy for this operation is usually low $\left(0.5-2 \mathrm{MJ} \mathrm{kg}^{-1}\right.$ PHA) and it is not considered a critical issue.

(3) Separating the extraction residues (non-PHA biomass and eventually water) from the PHA-enriched phase (usually the organic solvent). This step can be accomplished through filters or other solid/liquid separations (centrifuge, settling) which typically give a PHA-enriched liquid phase (PHA dissolved in the solvent) with a low amount of residual solvent (that can be recovered up to a certain level). This step is usually favored when water-insoluble organic solvents with low viscosity are used since they can be easily separated from the aqueous slurries.

(4) Separating PHA from the solvent by evaporation of a low boiling solvent or by PHA precipitation followed by solid/liquid separation. Evaporation of the solvent can be made by distillation (providing heat) or by lowpressure evaporation (providing electrical energy). PHA precipitation can be obtained by changing the physical properties of the solvent (e.g., temperature) or by admixing it with a counter-solvent that dissolves the solvent but not PHA. Solvent evaporation is the simplest and most widely applied solution, but it represents a costly step. Thermal energy consumption is directly proportional to the Latent Heat of Evaporation (LHE, ranging from $2.3 \mathrm{MJ} \mathrm{kg}-1$ for water to $0.4-1 \mathrm{MJ} \mathrm{kg}^{-1}$ for most common organic 


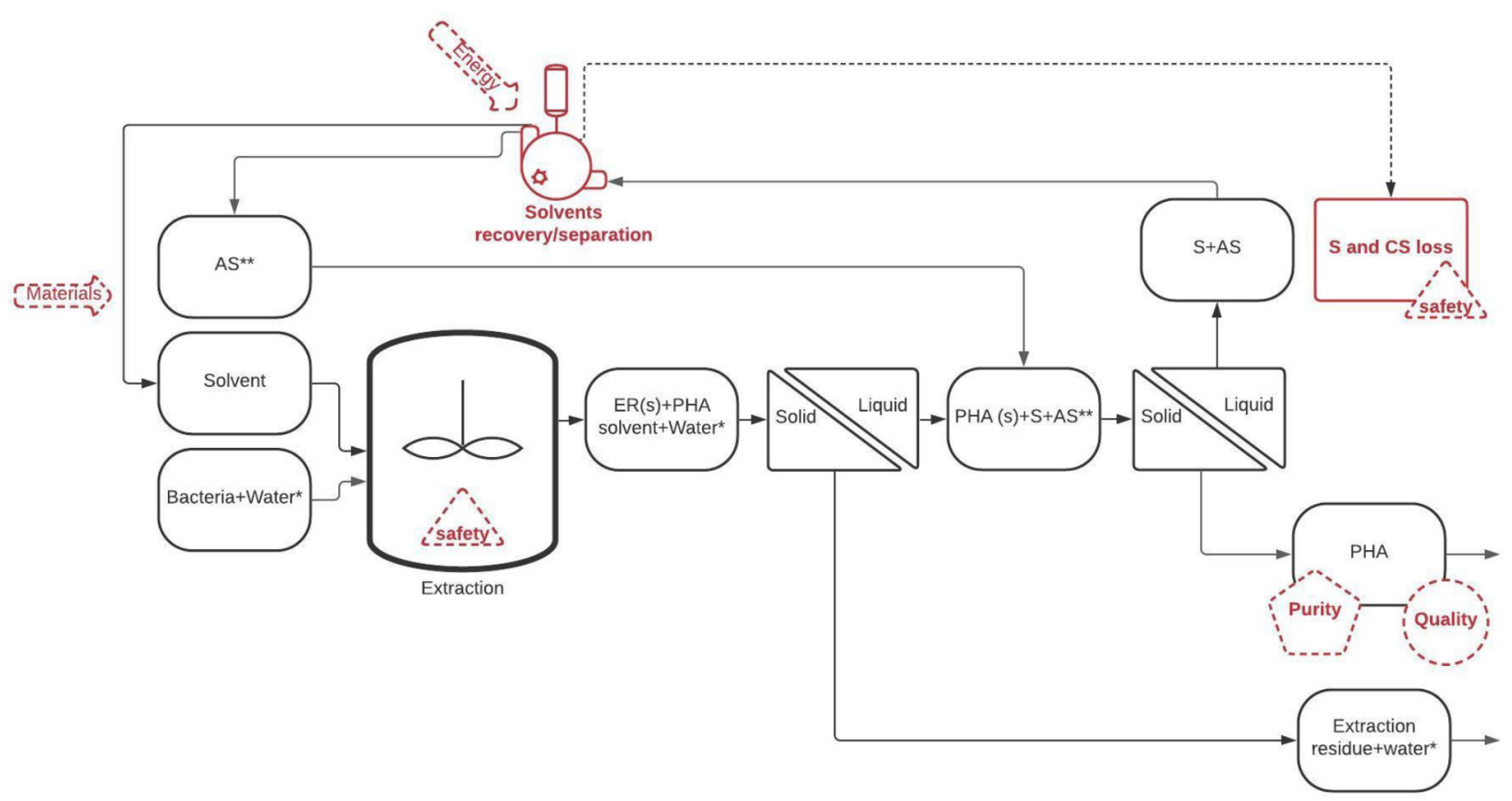

FIGURE 1 | General scheme representing the solvent-based approach for recovering PHA from PHA rich bacteria. AS, anti-solvent; S, solvent; PHA, polyhdroxyalkanoate; PHA (s), polyhydroxyalkanoate in suspended solid form; ER (s), extraction residue as suspended solids. *If the extraction is performed directly on wet microbial slurry. ${ }^{*} \mid f$ an anti-solvent is used.

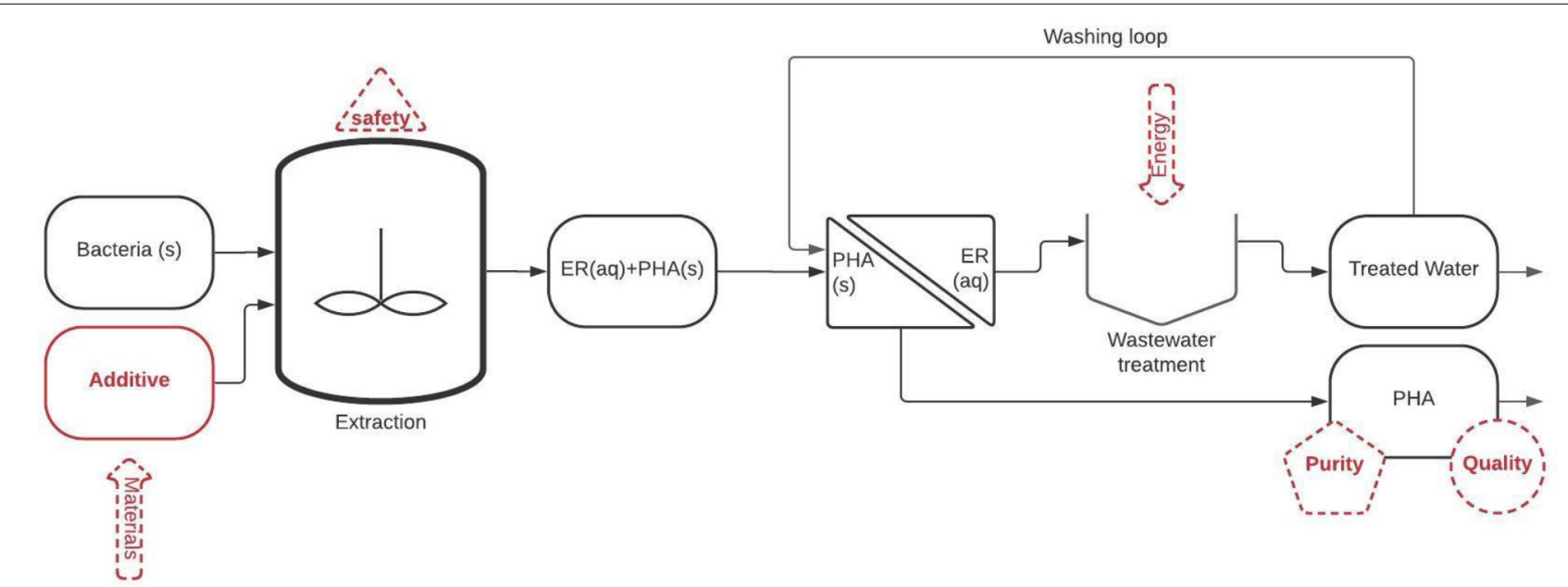

FIGURE 2 | General scheme representing the cellular lysis approach for recovering PHA form PHA rich bacteria. ER (aq), extraction residue dissolved in water; PHA, polyhydroxyalkanoate; PHA (s), polyhydroxyalkanoate in suspended solid form.

solvents and $\mathrm{CO}_{2}$ ), but "quality" of such thermal energy and therefore costs are related to the boiling temperature. This means that the organic solvents with low boiling point and low LHE are the easiest solvents to be removed.

(5) Re-obtaining of the solvent with a quality (purity) comparable with that of fresh solvent used for the extraction. This means that the solvents (or mixtures of solvent and antisolvent) should be processed to recover the largest portion in relatively clean form. For that purpose, precipitation of PHA has the unique feature to provide a direct recovery of the solvent during the separation stage. Otherwise, in most approaches both solvent and additional antisolvent can be recovered by condensation of the solvent vapors eventually assisted by a membrane separation or pervaporation (e.g., for the separation of miscible solvents). As a general rule-of-thumb, recovery by simple condensation is technically easier for compounds with high boiling points. When more complex methods, as 
membrane separation and pervaporation, are used to assist the solvent recovery, the efficiency is case-by-case related to the available membrane and affinity with solvents and potential interfering substances.

Due to the complexity of the process, four common/key critical issues can be identified in each solvent-based PHA extraction method:

(1) The efficiency related to solvent consumption: organic solvents cannot be $100 \%$ recovered because of leaks, losses (solvents remaining in PHA and extraction residues) and unavoidable safety needs. Even when a closed loop of solvent flow is used, a certain degree of system purging is required to avoid the formation of an explosive atmosphere.

(2) The efficiency related to the energy applied for solvent recovery: it is possible to significantly increase the solvent recovery by using higher energy and more complex equipment. The main drawback of this approach is the net energy consumption of the process as for the solvent evaporation under vacuum or the use of pervaporation through membranes.

(3) The solvent contaminations in the recovered PHA: whereas solvent extraction can be selective and could discriminate between PHA and other (polar) cellular constituents, the intrinsic affinity of the solvent for the polymer could hamper a complete solvent removal from the final product. Such aspect is quite relevant due to problems during the subsequent PHA processing (damage of injection molding equipment) and PHA utilization in the case of toxic solvents.

(4) Safety issues: all solvents but water is at least flammable and, in some cases, volatile. This means that they can accidentally form an explosive atmosphere, they can exert toxicity toward humans through respiratory systems or, being Volatile Organic Compounds (VOCs), they can cause air pollution.

The main steps involved in cellular lysis methods are presented in Figure 2.

(1) Mixing of PHA containing slurry and an additive (e.g., alkali, surfactants, or oxidants), eventually assisted by heating to improve the solubilization of non-PHA constituents. This operation produces slurry in which PHA becomes the main insoluble constituent.

(2) Separation of the slurry into a liquid solution and solid PHA usually recovered as a wet powder that must be dried and subsequently purified.

(3) Treating of the liquid solution, containing additives and solubilized bacterial biomass, as wastewater.

The main challenges of cellular lysis methods are:

(1) The soluble biomass constituents end up in the final PHA products, and, given that the dissolution process cannot be $100 \%$ efficient, the purity of the final PHA is typically the most relevant issue of such methods. This is especially important considering that impurities (e.g., endotoxins) could exert a negative effect on PHA applications (especially biomedical ones): pyrogenic endotoxin in fact causes fever if introduced into the bloodstream of humans or other animals and thus should be kept below a set limit. According to the U.S. Food and Drug Administration guideline, the upper pyrogen limit is 5.0 endotoxin units (EU)/kg (body weight) per injection.

(2) Whereas the energy input is typically lower than that necessary for solvent extractions, material consumption can be comparable or even larger than in solvent extraction methods. It follows that the recovery or saving of lytic agents through innovative approaches represents one of the challenges of the applied research concerning PHA extraction.

\section{Techno-Economics of the Extraction Process}

The PHA extraction process is strictly ruled by operational costs (OPEX) and fixed cost (CAPEX) of the extraction apparatus like all the other industrial processes. Beyond standard solid/fluid handling systems, which give a minor contribution to the system, the extraction apparatus is constituted by functional elements with a characteristic size (e.g., volume, power, or throughput capacity) that determine the CAPEX, and consumptions (power or material consumption) that determine the OPEX.

The OPEX $(€ / y)$ of a specific extraction system with a known capacity (kgPHA/y) are the actual yearly costs due to the equipment running, like electrical energy (purchased at $0.12 € / \mathrm{kWh}$ ) or thermal energy (purchased at $0.06 € / \mathrm{kWh}$ ). Such values can be calculated from basic assumptions of plant economics in chemical engineering.

The capital expenditure (CAPEX) consists of the purchasing costs of the extraction equipment $(€)$ and increases the "financial" yearly cost depending on the maintenance costs, equipment depreciation, amortization, and interest rate. Maintenance costs are a tangible value related to the fact that any equipment requires to be maintained, and the cost of maintenance is proportional to the CAPEX. Maintenance costs are estimated at 3-7\% of the CAPEX, with lower maintenance costs for mature technologies and large-scale plants, and higher maintenance costs for new technologies and small-scale equipment. Such values should be integrated with the other financial aspects (e.g., amortization over 20 years of plant operation) which add a value of $5-8 \%$ depending on the interest rate. As general rules of thumb, 1 $\mathrm{M} €$ of additional CAPEX implies a yearly cost equal to $70-150$ $\mathrm{k} € / \mathrm{y}$. Therefore, estimating the order of magnitude of the CAPEX of a certain extraction technology has pivotal importance for the early development stage of the technology itself. Consistent delivery of this information is not trivial and requires crossing the information from general plant economics with additional information from gray literature, namely quotations and opinion of experts working in similar fields. The scope of this review is to provide a comparison of methods from several points of view, therefore, some general rules to estimate the costs of an extraction process were drawn. This task was performed by focusing on the major (from the point of view of cost) extraction 
steps shown in Figures 1, 2: (i) the material input needed for the extraction (e.g., solvents or additives), (ii) the extraction reactor, (iii) the solid/liquid separator, and (iv) the solvent/water recovery/removal unit.

\section{Material Input}

The first relevant cost of each extraction procedure is related to the material input (additive, solvent or anti-solvent), named $\operatorname{OPEX}_{M}\left(€ / \mathrm{kg}_{P H A}\right)$ :

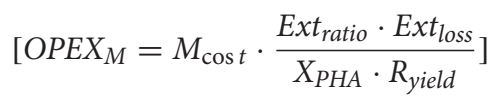

Where $M_{\text {cost }}$ is the market price $(€ / \mathrm{kg})$ of solvents/additives used, Ext ratio $\left(\mathrm{kg}_{M} / \mathrm{kg}_{\text {feedstock }}\right)$ is the specific amount of material used per kg of feedstock (e.g., biomass slurry), $\mathrm{X}_{P H A}$ is the PHA content of the feedstock $\left(\mathrm{kg}_{P H A} / \mathrm{kg}_{\text {feedstock }}\right), R_{\text {yield }}$ is the efficiency of extraction and $\mathrm{Ext}_{\text {loss }}$ is the amount of material that is lost at the end of the extraction process $\left(\mathrm{kg}_{M}\right.$, lost $\left./ \mathrm{kg}_{M, \text { used }}\right)$. $\mathrm{Ext}_{\text {loss }}$ ranges between 1 (e.g., a single-use surfactant) and 0 (when the solvent is completely recovered without any loss). For solvents, Ext $_{\text {loss }}$ depends on leaks (usually less than 1\%, Kemper, 1997) and the amount of residual solvent in the extracted product (solvent in PHA) and byproducts (solvent in the microbial residue). Overall $\mathrm{Ext}_{\text {loss }}$, which usually falls in the 0.005-0.05 range, but is deeply influenced by the chemistry of the system and process configuration.

\section{Extraction Reactor}

The extraction reactor consists of devices that pretreat/mix bacteria, solvents, and/or additives and manages the heating/cooling of the mixture, usually through electrical heating and a heat exchanger (since the extraction process is not significantly exo- or endothermic). The cost of the extraction reactors is mostly a function of the reactor volume (L) and relative operating pressure (bar). Being mixing almost negligible for the energy balance, the operating costs of the extraction reactor are mainly due to the heating of the mixture. Such aspects have been included in empirical relationships shown in the following equations, which can be used as a rule of thumb in the early design of new extraction processes. The CAPEX related cost (actualized considering depreciation and maintenance) of extraction vessel can be estimated as CAPEX $\mathrm{Cxtr.vessel}_{\text {( }}\left(€ / \mathrm{kg}_{P H A}\right)$ :

$$
\begin{aligned}
{\left[\text { CAPEX }_{\text {extr.vessel }}=\right.} & \frac{0.1}{8760} \cdot \frac{(1+0.0376 P)}{\sqrt{P H A_{\text {out }}}} \cdot 528 \\
& \left.\left(\frac{R T_{\text {ext }} \cdot\left(1+\text { Ext }_{\text {ratio }}\right)}{X_{\text {PHA }} \cdot R_{\text {yield }} \cdot \rho_{\text {mix }}}\right)^{0.5}\right]
\end{aligned}
$$

Where $\mathrm{P}$ is the relative pressure of extraction process (bar), $\mathrm{PHA}_{\text {out }}$ is the absolute size of the system expressed as PHA output capacity $\left(\mathrm{kg}_{P H A} / \mathrm{h}\right), \mathrm{RT}_{\text {ext }}$ is the residence time in extraction vessel, Ext ratio $\left(\mathrm{kg}_{M} / \mathrm{kg}_{\text {feedstock }}\right)$ is the specific amount of material used per $\mathrm{kg}$ of feedstock (e.g., biomass slurry), $\mathrm{X}_{P H A}$ is the PHA content of the feedstock $\left(\mathrm{kg}_{P H A} / \mathrm{kg}_{\text {feedstock }}\right), \mathrm{R}_{\text {yield }}$ is the efficiency of extraction $\left(\mathrm{g}_{P H A}\right.$,extracted $\left./ \mathrm{g}_{P H A}\right)$, and $\rho_{\text {mix }}(\mathrm{kg} / \mathrm{L})$ is the density of the mixture in the extraction vessel (e.g., $0.7-1.5 \mathrm{~kg} / \mathrm{L}$ water and organic solvents).

The specific OPEX extr.vessel $\left(€ / \mathrm{kg}_{P H A}\right)$ of the extraction reactor running is mainly related to the heating or pretreatment of the mixture as follows:

$$
\begin{aligned}
{\left[\mathrm{OPEX}_{\text {extr.vessel }}\right.} & =\frac{T h E_{\text {price }} \cdot \Delta T \cdot C_{p}\left(1+\text { Ext }_{\text {ratio }}\right)}{3.6 \cdot 10^{6} \cdot X_{P H A} \cdot R_{\text {yield }}} \\
+ & \left.\frac{E l E_{\text {price }} \cdot E n_{\text {req }} \cdot R T_{\text {ext }}\left(1+\text { Ext }_{\text {ratio }}\right)}{3.6 \cdot 10^{6} \cdot X_{P H A} \cdot R_{\text {yield }} \cdot \rho_{\text {mix }}}\right]
\end{aligned}
$$

Where $\mathrm{ThE}_{\text {price }}$ and $\mathrm{ElE}_{\text {price }}$ are respectively the thermal and electrical energy costs $(€ / \mathrm{kWh}), \Delta \mathrm{T}$ is the difference between the inlet and outlet temperatures (equal to the reaction temperature) and minus environmental temperature if heat recovery is not applied, $C_{p}$ is the specific heat capacity of extraction mixture, Ext $_{\text {ratio }}\left(\mathrm{kg}_{M} / \mathrm{kg}_{\text {feedstock }}\right)$ is the specific amount of material used per $\mathrm{kg}$ of feedstock (e.g., biomass slurry), $\mathrm{X}_{P H A}$ is the PHA content of the feedstock $\left(\mathrm{kg}_{P H A} / \mathrm{kg}_{\text {feedstock }}\right), \mathrm{R}_{\text {yield }}$ is the efficiency of extraction, $\mathrm{En}_{\text {req }}$ is the electrical energy required per unit of volume ( $\mathrm{W} \mathrm{L}^{-1}$, e.g., heat dissipation, stirrers, mixers or ultrasound treatment), $\mathrm{RT}_{\text {ext }}$ is the residence time in extraction vessel, $\rho_{\text {mix }}$ is the density of the mixture in the extraction vessel (e.g., $0.7-1.5 \mathrm{~kg} / \mathrm{L}$ water and organic solvents). OPEX $\mathrm{Cxtr}_{\text {vessel }}$ is not intrinsically related to the scale of the extraction, even if $\mathrm{En}_{\text {req }}$ can be affected by the scale, with a general lower volumetric energy requirement for larger reactors.

\section{Solid/Liquid Separator}

A solid/liquid separation can be performed using tangential filtration, dead-end filtration (e.g., industrial filter press), or centrifugation. Each separation technique is characterized by different applicability and economic features. Tangential filtration is usually characterized by high OPEX, mainly due to recirculation pumping required, and low fixed cost, consisting of filtration elements. As a comparison, filter presses and centrifuges are characterized by high CAPEX and lower OPEX, and for this reason are the best options at a larger scale, when scale factor decreases selectively the CAPEX related cost.

The tangential filtration unit is formed by filters and recirculation pump needed for tangential low through the filters and can be used as a general model for a preliminary cost evaluation. The cost of such systems is mainly related to the CAPEX and can be easily modeled as an example technology for S/L separation:

$$
\begin{aligned}
& {\left[\text { CAPEX }_{S / L}=\frac{0.1}{8760} \cdot \frac{3000}{P H A_{\text {out }}^{0.23}} \cdot\right.} \\
& \left.\qquad\left(\frac{\text { Filtrate }_{\text {ratio }} \cdot\left(1+\text { Filtrate }_{\text {wash loop }}\right)}{\text { Filter }_{\text {rate }} \cdot X_{P H A} \cdot R_{\text {yield }} \cdot \rho_{\text {filtrate }}}\right)^{0.77}\right]
\end{aligned}
$$

Where $\mathrm{PHA}_{\text {out }}$ is the absolute size of the system expressed as PHA output capacity $\left(\mathrm{kg}_{P H A} / \mathrm{h}\right)$, Filtrate ratio $_{\text {is }}$ the specific amount of external input (e.g., solvent or aqueous additive) that has to be obtained as filtrate through $\mathrm{S} / \mathrm{L}$ module, Filtrate washloop $_{\text {is }}$ the 
times that the solid has to be washed to get an acceptable purity, Filter $_{\text {rate }}\left(\mathrm{L} / \mathrm{m}^{2} / \mathrm{h}\right)$ is the specific filtration capacity of the filtration equipment, which depends on the filter (mainly the size of pores) and liquid viscosity, $\mathrm{X}_{P H A}$ is the PHA content of the feedstock $\left(\mathrm{kg}_{P H A} / \mathrm{kg}_{\text {feedstock }}\right), \mathrm{R}_{\text {yield }}$ is the efficiency of extraction, $\rho_{\text {filtrate }}$ $\left(\mathrm{kg} \mathrm{L}^{-1}\right)$ is the density of filtrate. Typical values of Filter ${ }_{\text {rate }}$ in microfiltration (the most used system for separation of cells or cellular debris in aqueous slurries) is around $35 \mathrm{~L} / \mathrm{m}^{2} / \mathrm{h}$ and the updated 2020 cost for microfiltration elements is around 3000 $€ / \mathrm{m}^{2}$ filtration area.

$\mathrm{OPEX}_{S / L}\left(€ / \mathrm{kg}_{P H A}\right)$ of tangential filtration are mainly related to the recirculation pump which is about 200-folds larger than feed pumps and determines most of the energy consumption of the system:

$\left[\right.$ OPEX $\left._{\frac{S}{L}}=\frac{\text { ElE }_{\text {price }} \cdot P W_{E, \text { reg }} \cdot \text { TFlow }_{\text {ratio }} \cdot\left(1+\text { Filtrate }_{\text {wash loop }}\right)}{3.6 \cdot 10^{6} \cdot X_{P H A} \cdot R_{\text {yield }} \cdot \rho_{\text {filtrate }}}\right]$

Where ElE $_{\text {price }}$ is respectively the electrical energy price $(€ / \mathrm{kWh})$, $\mathrm{PW}_{E}$ req is the work required for pumping $1 \mathrm{~L}$ of slurry (e.g., 360-600 J/L for large volumetric pumps working at differential pressure of 2-4 bar), TFlow ${ }_{\text {ratio }}$ is the ratio between tangential flow and filtrate flow required to avoid plugging of filters (e.g., typically in the 100-300 range), $\operatorname{Ext}_{\text {ratio }}\left(\mathrm{kg}_{M} / \mathrm{kg}_{\text {feedstock }}\right)$ is the specific amount of material used per $\mathrm{kg}$ of feedstock (e.g., biomass slurry), $X_{P H A}$ is the PHA content of the feedstock $\left(\mathrm{kg}_{P H A} / \mathrm{kg}_{\text {feedstock }}\right), R_{\text {yield }}$ is the efficiency of extraction, $\rho_{\text {filtrate }}(\mathrm{kg}$ $\mathrm{L}^{-1}$ ) is the density of filtrate.

\section{Solvent Recovery or Drying Unit (SRU)}

Solvent recovery (or water removal) can be accomplished through atmospheric distillation, vacuum distillation or pervaporation through a membrane. Atmospheric distillation is characterized by high OPEX and low CAPEX, whereas vacuum distillation or pervaporation save OPEX at the expense of higher CAPEX. Despite the large variability of technologies, a base-case in which the solvent is recovered by distillation at atmospheric pressure can be considered: such conventional evaporation of organic solvents can remove a solvent from a solid material (e.g., solvent + PHA) and requires an amount of energy slightly higher than the latent heat of evaporation due to solvent losses. An important aspect is that, when distillation is applied to a solid-free mixture (e.g., solvent + anti-solvent mixture) and especially with water, multiple-effect distillation can be used, decreasing the energy requirement down to $4 \%$ of the latent heat of evaporation.

For simpler evaporators that can be used for both water evaporation and solvent recovery the CAPEX $\mathrm{Cvaporator}\left(€ / \mathrm{kg}_{\text {PHA }}\right)$ is intrinsically related to the amount of heat exchange required, and ultimately on the surface area of heat exchangers. Such size is proportional to the amount of heat involved in the evaporation and the number of effects used in multiple effect evaporators. The 2020 cost of evaporators with a $0.5-0.6 \mathrm{MW}$ latent heat capacity $\left(0.7-0.8\right.$ ton $\left._{H 2 O} / \mathrm{h}\right)$ is in the $1.2-1.8 \mathrm{M} €$ range. Taking average values from quotation and, including some empirical assumptions, the CAPEX related costs associated with that step can be estimated as follows:

$$
\left[C A P E X_{\text {evaporator }}=\frac{0.1}{8760} \cdot \frac{72}{P H A_{\text {out }}^{0.23}} \cdot\left(\frac{n_{\text {eff }} \cdot L_{v} \cdot E x t_{\text {ratio }}}{3600 \cdot X_{P H A} \cdot R_{\text {yield }}}\right)\right]
$$

Where $n_{\text {eff }}$ is the number of effects used if multiple-effect evaporation is used ( $n_{\text {eff }}$ equal to 1 for simple drying processes), $L_{v}$ is the latent heat of evaporation (e.g., $2.210^{6} \mathrm{~J} / \mathrm{kg}$ for water), $\operatorname{Ext}_{\text {ratio }}\left(\mathrm{kg}_{M} / \mathrm{kg}_{\text {feedstock }}\right)$ is the specific amount of material used per $\mathrm{kg}$ of feedstock (e.g., biomass slurry), $\mathrm{X}_{P H A}$ is the PHA content of the feedstock $\left(\mathrm{kg}_{P H A} / \mathrm{kg}_{\text {feedstock }}\right), \mathrm{R}_{\text {yield }}$ is the efficiency of extraction. OPEX evaporator $\left(€ / \mathrm{kg}_{P H A}\right)$ is described by the following equation:

$$
\left[O P E X_{\text {evaporator }}=\frac{T h E_{\text {price }} \cdot L_{v} \cdot \text { Ext }_{\text {ratio }}}{3.6 \cdot 10^{6} \cdot X_{P H A} \cdot R_{\text {yield }} \cdot n_{\text {eff }}}\right]
$$

Where $T h E_{\text {price }}$ is the thermal energy cost $(€ / \mathrm{kWh}), \mathrm{L}_{v}$ is the latent heat of evaporation (e.g., $2.210^{6} \mathrm{~J} / \mathrm{kg}$ for water), Ext ${ }_{\text {ratio }}$ $\left(\mathrm{kg}_{M} / \mathrm{kg}_{\text {feedstock }}\right)$ is the specific amount of material used per $\mathrm{kg}$ of feedstock (e.g., biomass slurry), $\mathrm{X}_{P H A}$ is the PHA content of the feedstock $\left(\mathrm{kg}_{P H A} / \mathrm{kg}_{\text {feedstock }}\right), \mathrm{R}_{\text {yield }}$ is the efficiency of extraction, $\mathrm{n}_{\text {eff }}$ is the number of effects used if multiple-effect evaporation is used ( $\mathrm{n}_{\text {eff }}$ equal to 1 for simple drying processes).

Both CAPEX evaporator $_{\text {and }} \mathrm{OPEX}_{\text {evaporator }}$ are proportional to

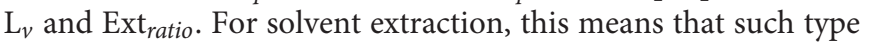
of costs is minimized with the use of a solvent with low $\mathrm{L}_{v}$ (e.g., weak intermolecular bonds) and high efficiency (which means lower $\mathrm{Ext}_{\text {ratio }}$ ). Increasing $\mathrm{n}_{\text {eff }}$ decreases the OPEX $\mathrm{O}_{\text {evaporator }}$ but increases $\mathrm{CAPEX}_{\text {evaporator }}$ and this means that this parameter should be optimized according to the size of the equipment.

Applying the abovementioned formulas to some PHA extraction examples gives a general idea of the main cost issue of different extraction procedures. Nonetheless, it should be pointed out that this is just an example of a possible application of an economic analysis that can be used to evaluate the order of magnitude of costs in the infancy of process development at low Technology Readiness Level (TRL), to drive the design toward more economically sustainable processes. At high TRLs, a more detailed analysis is mandatory to provide a go-not-go decision.

A comparison of the estimated costs for two hypothetical PHA extraction processes (extraction with chloroform at $60^{\circ} \mathrm{C}$, with $\mathrm{CHCl}_{3}$ : biomass ratio of 20:1; cellular lysis with $\mathrm{NaClO} 1.9 \mathrm{M}$ at $37^{\circ} \mathrm{C}$ for $1 \mathrm{~h}$ ) is reported in Figure 3. Ex ante evaluation of the cost of the two extraction processes gives values of $0.7-$ $1.3 € / \mathrm{kg}$, close to the values obtained through a more detailed economic analysis performed by Fernández-Dacosta et al., 2015. Summing up this value with $0.8-1 € / \mathrm{kg}_{P H A}$ feedstock cost (e.g., PHA from $0.4 € / \mathrm{kg}$ glucose with $30-40 \%$ yield) and cost for single strain cultivation $\left(0.8-1.8 € / \mathrm{kg}_{P H A}\right)$, we could calculate the PHA production cost within $2.3-4.3 € / \mathrm{kg}_{P H A}$ range. Such data fit with a $1.4-4 € / \mathrm{kg}_{P H A}$ realistic market price using current technologies.

This calculation highlights that cellular lysis can be considered as a low-cost extraction process that can be applied to produce low-cost and low-quality PHA even if the quite high cost of the material input. On the other hand, chlorinated solvents (characterized by the high cost of SRU) become competitive at a large scale and when PHA quality requirement prevents the 


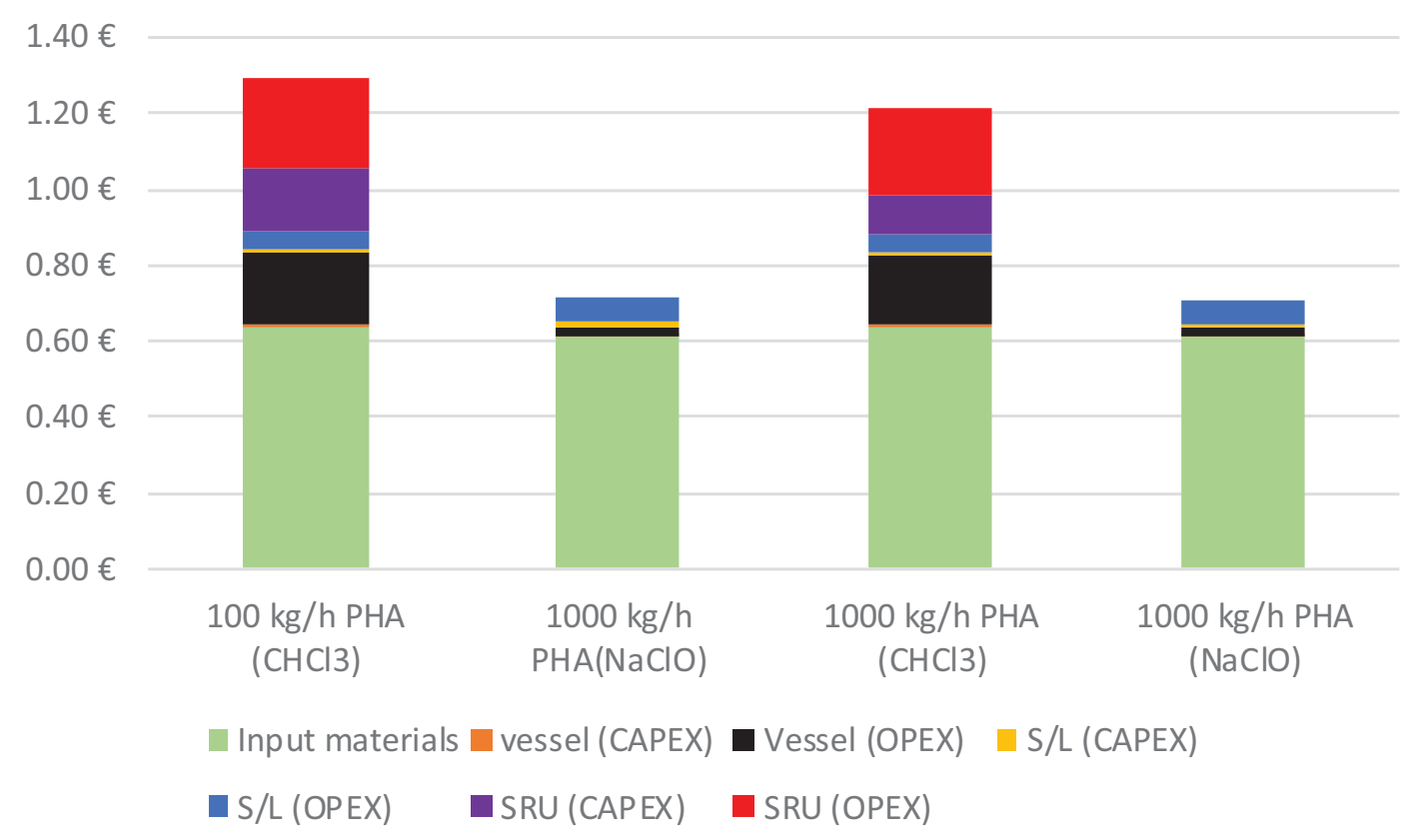

FIGURE 3 | Analysis of major sources of costs of two PHA extraction processes (extraction with $\mathrm{CHCl}_{3}$ and cellular lysis with $\mathrm{NaClO}$ ).

use of harsh cellular lysis methods. This is in line with life cycle costing (LCC) and LCA studies focused on PHA recovery from single microbial strains reported in the literature (Saavedra del Oso et al., 2020). They reveal that:

- methods based on cellular lysis with alkaline compounds or surfactants have lower costs $\left(1.02-5.23 € / \mathrm{kg}_{P H A}\right)$ than those based on solvent extraction (1.95-6.61 €/ $\left.\mathrm{kg}_{P H A}\right)$,

- methods based on cellular lysis have better environmental performance (0.81-4.16 $\left.\mathrm{kg} \mathrm{CO}_{2 e q}\right)$ than those based on solvent extraction (3.93-12.96 kg CO $\mathrm{CO}_{2 e q}$ ),

- chemicals and heat production cover more than 50\% and 20-30\%, respectively, of the total operating costs and are the main contributors to environmental impacts of both processes, underlying the need of reducing energy use, employing greener energy sources, and introducing chemicals recovery units where it is possible.

- PHA extraction through solvents needs large amounts of energy, especially for solvent-recovery; thus, it seems a suitable approach just for these applications in which high-quality PHA is required. However, economic and environmental performance can be optimized by employing more easily recoverable solvents, utilizing the residual heat of the PHA production plant, or process byproducts exploitable as solvents.

\section{EXTRACTION OF PHA FROM SINGLE MICROBIAL STRAINS}

The research on PHA production has been focused from the beginning on the utilization of single strain cultures, and the few industrial realities that are currently producing PHA for the market are based on this approach (e.g., Biomer, Kaneka, Danimer Scientific). Different bacterial strains have been successfully used to synthesize biopolymers such as Alcaligenes eutrophus, Alcaligenes latus, Azotobacter vinelandii, Azotobacter chroococcum, Azotobacter beijerincki, methylotrophs, Pseudomonas spp., Bacillus spp., Rhizobium spp., Nocardia spp., and recombinant Escherichia coli (Pagliano et al., 2017). These bacteria can accumulate PHAs under extreme conditions such as excess carbon source and/or nutrient (nitrogen, phosphorus, sulfur, or oxygen) starvation (Reddy et al., 2003). Single strains have the double advantage to be able to accumulate a high PHA amount (above $80 \%$ of the cell dry weight) (Reis et al., 2003) and to reach high cell densities. On the other hand, such fermentations have high operating costs mainly associated with raw material and sterilization phase (Morgan-Sagastume et al., 2010).

\section{Solvent Extraction Methods Applied to Single Microbial Strains Halogenated Solvents}

Chloroform, dichloromethane, 1,2-dichloroethane, 1,1,2trichloroethane, and 1,1,2,2-tetrachloroethane are the solvents of choice for PHA extraction since very pure polymers (more than $90 \%$ ) with high molecular weight (up to $1.2 \mathrm{MDa}$ ) can be easily obtained (Table 1); therefore halogenated compounds are often considered as the benchmark solvents for PHA recovery (Koller et al., 2013). On the other hand, a quite wide polydispersity index range is often observed (1.75-4.50). The extraction yields seem influenced by two factors, even if a clear independent effect of all of them is difficult to be highlighted: 
TABLE 1 | PHAs extraction from single strains with solvents.

\begin{tabular}{|c|c|c|c|c|c|c|c|}
\hline Solvent class & Solvent type and extraction conditions & $\begin{array}{l}\text { PHA type and } \\
\text { content (wt } \%)\end{array}$ & Recovery (\%) & Purity (\%) & $\begin{array}{c}\text { Molecular } \\
\text { weight (MDa) }\end{array}$ & $\begin{array}{l}\text { Polydispersity } \\
\text { index (PDI) }\end{array}$ & References \\
\hline \multirow[t]{17}{*}{$\begin{array}{l}\text { Halogenated } \\
\text { solvents }\end{array}$} & $\mathrm{CHCl}_{3}\left(25^{\circ} \mathrm{C}\right)$ & PHB (50) & 27 & 95 & 1.2 & - & $\begin{array}{l}\text { Ramsay et al., } \\
1994\end{array}$ \\
\hline & $\mathrm{CHCl}_{3}\left(61^{\circ} \mathrm{C}\right)$ & $\mathrm{PHB}(50)$ & 55 & 92 & 0.9 & - & $\begin{array}{l}\text { Ramsay et al., } \\
1994\end{array}$ \\
\hline & $\mathrm{CHCl}_{3}\left(61^{\circ} \mathrm{C}\right.$, acetone pretreatment) & $\mathrm{PHB}(50)$ & 68 & 96 & 0.9 & - & $\begin{array}{l}\text { Ramsay et al., } \\
1994\end{array}$ \\
\hline & $\mathrm{CHCl}_{3}\left(4^{\circ} \mathrm{C}\right)$ & PHB (62) & - & - & $0.8-1.0$ & $3.1-3.7$ & $\begin{array}{l}\text { Cavalheiro } \\
\text { et al., } 2009\end{array}$ \\
\hline & $\mathrm{CHCl}_{3}\left(37^{\circ} \mathrm{C}\right)$ & PHB (38) & 31 & 92 & 0.8 & 2.6 & $\begin{array}{l}\text { Valappil et al., } \\
2007\end{array}$ \\
\hline & $\mathrm{CHCl}_{3}\left(37^{\circ} \mathrm{C}, \mathrm{NaClO}\right.$ pretreatment $)$ & PHB (38) & 27 & 99 & 1.1 & 1.7 & $\begin{array}{l}\text { Valappil et al., } \\
2007\end{array}$ \\
\hline & $\mathrm{CHCl}_{3}$ and $\mathrm{NaClO}\left(30^{\circ} \mathrm{C}\right)$ & PHB (67) & - & 97 & 1.0 & 2.0 & $\begin{array}{l}\text { Hahn et al., } \\
1993\end{array}$ \\
\hline & $\mathrm{CHCl}_{3}\left(\mathrm{NaClO}\right.$ and $\mathrm{NaHSO}_{3}$ pretreatment) & PHB (55) & - & 97 & 0.6 & - & $\begin{array}{l}\text { Suk Roh et al., } \\
1995\end{array}$ \\
\hline & $\mathrm{CHCl}_{3}$ and $\mathrm{NaClO}$ (Al-, Fe-coagulants pretreatment) & $\mathrm{PHB}$ & $90-94$ & $98-99$ & - & - & Ryu et al., 2000 \\
\hline & $\mathrm{C}_{2} \mathrm{H}_{4} \mathrm{Cl}_{2}\left(83^{\circ} \mathrm{C}\right)$ & PHB (50) & 54 & 92 & 0.8 & - & $\begin{array}{l}\text { Ramsay et al., } \\
1994\end{array}$ \\
\hline & $\mathrm{C}_{2} \mathrm{H}_{4} \mathrm{Cl}_{2}\left(83^{\circ} \mathrm{C}\right.$, acetone pretreatment) & $\mathrm{PHB}(50)$ & 69 & 97 & 0.8 & - & $\begin{array}{l}\text { Ramsay et al., } \\
1994\end{array}$ \\
\hline & $\mathrm{CH}_{2} \mathrm{Cl}_{2}(\mathrm{rt})$ & $\mathrm{P}(\mathrm{HH}-\mathrm{HO})(30)$ & 86 & 78 & - & - & $\begin{array}{l}\text { Furrer et al., } \\
2007\end{array}$ \\
\hline & $\mathrm{CH}_{2} \mathrm{Cl}_{2}\left(40^{\circ} \mathrm{C}\right.$, acetone pretreatment $)$ & $\mathrm{PHB}(50)$ & 24 & 95 & 1.05 & - & $\begin{array}{l}\text { Ramsay et al., } \\
1994\end{array}$ \\
\hline & $\mathrm{CH}_{2} \mathrm{Cl}_{2}\left(60^{\circ} \mathrm{C}\right)$ & $\mathrm{P}(\mathrm{HB}-\mathrm{HV})(40)$ & - & 98 & $0.9-1.2$ & $2.7-3.3$ & $\begin{array}{l}\text { Zinn et al., } \\
2003\end{array}$ \\
\hline & $\mathrm{CH}_{2} \mathrm{Cl}_{2}$ & PHB (80) & - & 99 & - & - & Hrabak, 1992 \\
\hline & $\mathrm{CH}_{2} \mathrm{Cl}_{2}\left(35^{\circ} \mathrm{C}\right)$ & $\mathrm{PHO}(15-17)$ & $15-20$ & - & 0.1 & 3.8 & $\begin{array}{l}\text { Wampfler et al., } \\
2010 \mathrm{~b}\end{array}$ \\
\hline & $\mathrm{CH}_{2} \mathrm{Cl}_{2}\left(37^{\circ} \mathrm{C}, \mathrm{HCl}\right.$ pretreatment $)$ & $\mathrm{PHA}$ & - & 97 & $0.2-0.5$ & - & $\begin{array}{l}\text { Martínez et al., } \\
2011\end{array}$ \\
\hline \multirow[t]{3}{*}{ Alkanes } & Hexane (rt) & $\mathrm{P}(\mathrm{HH}-\mathrm{HO})(30)$ & 53 & 93 & 0.2 & 1.3 & $\begin{array}{l}\text { Furrer et al., } \\
2007\end{array}$ \\
\hline & Hexane $\left(30^{\circ} \mathrm{C}\right)$ & PHB (60) & 49 & $>99$ & 0.1 & - & $\begin{array}{l}\text { Manangan and } \\
\text { Shawaphun, } \\
2010\end{array}$ \\
\hline & Hexane $\left(50^{\circ} \mathrm{C}\right)$ & PHB (98) & 3 & 89 & - & - & $\begin{array}{l}\text { Aramvash } \\
\text { et al., } 2018\end{array}$ \\
\hline \multirow[t]{2}{*}{ Alcohols } & Medium chain-length alcohols & PHB (65-70) & 95 & $>98$ & $0.2-0.4$ & - & $\begin{array}{l}\text { Nonato et al., } \\
2001\end{array}$ \\
\hline & $\mathrm{EtOH} / \mathrm{H}_{2} \mathrm{O}\left(30^{\circ} \mathrm{C}\right)$ & PHA (30) & 96 & 81 & 0.3 & 2.6 & $\begin{array}{l}\text { Mohammadi } \\
\text { et al., 2012a }\end{array}$ \\
\hline
\end{tabular}


TABLE 1 | Continued

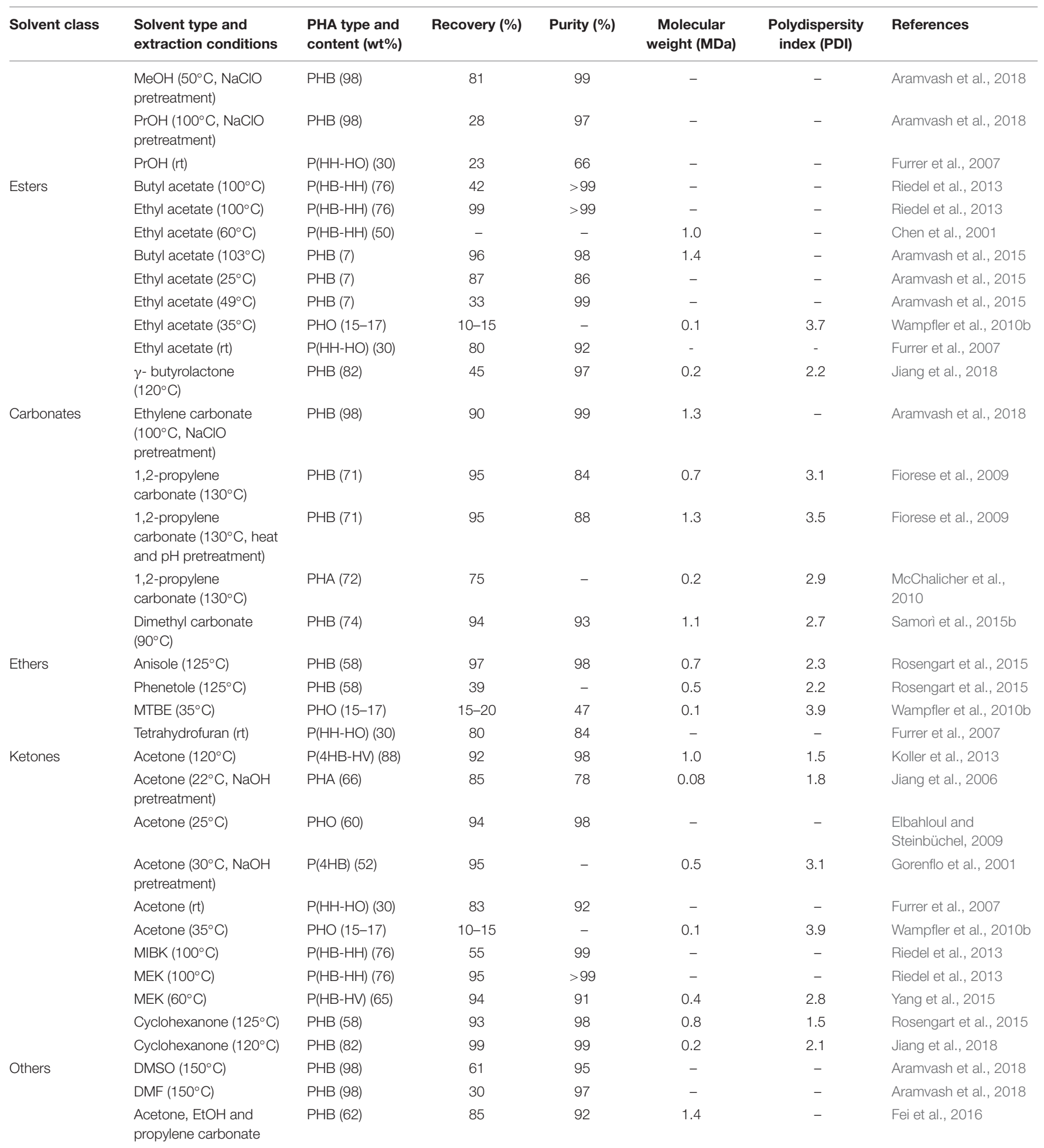

The investigated parameters are the solvents used for the extraction, the initial content of PHA in bacteria (wt\% by dry weight) and the recovery (\%), and the properties of the extracted PHA (purity\%, molecular weight in MDa and polydispersity index). 
1. the solvent type: the recovery of PHA from single strains with a polymer amount of $50 \%$ is similar if 1,2-dichloroethane or chloroform are used under their reflux temperature, whereas the recovery with dichloromethane under the same conditions is almost four-times lower (Ramsay et al., 1990).

2. the temperature of the extraction process: Ramsay et al. (1990) demonstrated that the extraction of single strains containing $50 \mathrm{wt} \%$ of PHA with chloroform doubles by increasing the temperature from rt to the reflux one, but the same is not true when dichloromethane is used (results achieved at rt or under reflux are around $20 \%$ ).

Many attempts have been done to improve the extraction process mediated by halogenated solvents; the application of a pre-treatment by employing chemical (e.g., treatments with oxidants, salts, or alkaline compounds) and/or physical methods (e.g., heat treatment) seems to be the best choice to improve cell disruption, promote solvent permeation and enhance the accessibility to PHAs granules. Moreover, since the high solvent to biomass ratio necessary for getting a satisfying recovery, a pretreatment step could be necessary to reduce the amount of solvent itself, and, consequently, the costs.

If a pre-treatment of the microbial biomass with $\mathrm{NaClO}$ is performed before the extraction step, the PHA recovery drastically improves, especially in the case of dichloromethane (the polymer recovery is reported to increase up to $90 \%$, LópezAbelairas et al., 2015), whereas a pre-treatment with acetone does not substantially improve the results achieved without any pretreatment (Ramsay et al., 1990). $\mathrm{NaClO}$ is claimed to weaken the cell membranes, thus facilitating the subsequent extraction of PHA by solvents (Koller et al., 2013). The combination of a $\mathrm{NaClO}$ pre-treatment and the precipitation of PHA using alcohols gives the best extraction yields and purity value (recovery up to $94 \%$ and purity up to $99 \%$ ) (Berger et al., 1989; Ryu et al., 2000; López-Abelairas et al., 2015); this approach exploits the fact that PHA solubility is drastically minimized by adding a "PHA anti-solvent," typically low-molecular alcohols (ethanol or methanol), hexane, ether, acetone, or water (Koller et al., 2013), whereas impurities solubility should not be affected.

Despite being highly performing in terms of recovery yields and polymer properties, halogenated solvents are not ecofriendly, being hazardous for the environment and the operators; chloroform, for example, can affect the central nervous system and the liver, it is highly irritating for mucous membranes, the respiratory tract, and eyes, it is classified as possibly carcinogenic for humans (Group 2B, International Agency for Research on Cancer (IARC), 1999) and as Hazardous Air Pollutant, HAP (EPA Environmental Protection Agency (EPA), 1990). Additionally, halogenated solvents commonly used for PHA extraction are all fossil-based solvents. All these impactful aspects are worsened by the fact that high amounts of solvents are required for the extraction process and the large quantity of energy must be employed for the purification of the solvent and its reuse, making this approach not economically advantageous. Finally, it has been claimed that the natural morphology of the PHA granules can be affected by the use of halogenated solvents, which prevents the use of PHA for certain applications, for example in the production of strong fibers by reducing molecular mass via random and chain-end scission, particularly at a higher temperature and prolonged extraction time (Pérez-Rivero et al., 2019).

A solution to reduce the impact of these solvents on the environment and human health could be the utilization of halogen-free solvents like alkanes, alcohols, linear and cyclic esters and carbonates, ethers, ketones, organosulfur compounds, and amides (Table 1). Some of these solvents are not toxic for humans and granted GRAS (Generally Recognized As Safe) by Flavor and Extract Manufacturers Association (FEMA, Flavor and Extract Manufacturers Association), whereas others are bio-based: alcohols (ethanol and butanol) and acetone for example can be produced through biochemical approaches starting from renewable resources (e.g., alcoholic fermentations mediated by Saccharomyces cerevisiae or acetone-butanol-ethanol fermentation mediated by Chlostridia), whereas linear and cyclic carbonates (dimethyl carbonate or propylene carbonate) are $\mathrm{CO}_{2}$-derived solvents with low (eco)toxicity, complete biodegradability, and very low vapor pressure.

\section{Alkanes}

Alkanes used in the extraction of PHA from single strains (e.g., hexane) provide polymers with high purity $(89-\approx 100 \%)$ but in low yields and with low molecular weight (about 50\% and $0.2 \mathrm{MDa}$, respectively). This trend is surely due to the low solubility of PHA into such apolar solvents; on the other hand, this high lipophilicity is beneficial in terms of Gramnegative bacteria's endotoxins abatement, providing polymers useful for medical applications, especially if an anti-solvent is used for recovering PHA (Pérez-Rivero et al., 2019): a decrease in the "endotoxicity" of PHA from 100 endotoxic units (EU golymer ${ }^{-1}$ ) (Williams et al., 1994) to $10 \mathrm{EU} \mathrm{g}_{\text {polymer }}{ }^{-1}$ was achieved by using 2-propanol for precipitating PHA from $n$-hexane (Furrer et al., 2007). Despite the positive effect given by alkanes in terms of endotoxins abatement and thus health issue, alkanes cannot be considered as "green" solvents: hexane and pentane are "hazardous" compounds according to all the solvent selection guidelines published so far (Henderson et al., 2011; Prat et al., 2014, 2016), because of safety (high flammability) and environmental issues (ability to generate harmful Volatile Organic Compounds, VOC, hazardous to the atmospheric ozone layer), the last ones a common feature of longer alkanes like heptane. Therefore, the constraints on scaled-up processes based on these compounds are very strong, and their substitution during process development is a priority (Prat et al., 2016).

\section{Alcohols}

Contrary to alkanes, low-medium chain length alcohols are too polar solvents for being reliable candidates for PHA extraction. The fact that the extracted PHA have a low molecular weight (0.2-0.4 MDa) (Nonato et al., 2001; Mohammadi et al., 2012a) can be an indication that these polar solvents are suitable for "peculiar" polymers with short chains, presumably less difficult to be solubilized. A $\mathrm{NaClO}$ pre-treatment is often associated 
with alcohol extraction to achieve polymer purity up to $99 \%$ (Aramvash et al., 2018). As in the case of halogenated solvents, also for alcohols, the temperature affects the PHA recovery yield and purity (Mohammadi et al., 2012a): a combined synergic effect of ethanol and water has been reported by increasing the temperature from 4 to $30^{\circ} \mathrm{C}$, since an increasing interaction between water and ethanol improves the cell wall breakage. Water seems to cause the release of cellular proteins and exert an osmotic pressure on the cells that result easily breakable (Mohammadi et al., 2012b). Despite alcohols seem to have a narrow range of applicability in the PHA extraction scenario, their use in scaled-up processes would be strongly encouraged: alcohols, in fact, are generally recognized as "recommended" solvents, benign in terms of acute environmental toxicity and the bio-accumulation (Henderson et al., 2011; Prat et al., 2014; Prat et al., 2016), as well in terms of health issue (butanol, in particular, is granted GRAS by FEMA and synthesizable from renewable resources thus potentially bio-based).

\section{Esters}

The extraction protocols based on linear and cyclic esters reported in the literature are generally performed at a quite high temperature (around $100^{\circ} \mathrm{C}$ ); a direct comparison between ethyl and butyl acetate in the extraction of single strain bacteria containing $76 \mathrm{wt} \%$ of the copolymer $\mathrm{P}(\mathrm{HB}-\mathrm{HH})$, indicates the first as the best performing among the two in terms of recovery yields, whereas the purity is excellent with both (Riedel et al., 2013). If wet biomass is extracted, a double effect of water can be observed: the hydrolysis of the esters and the reduction of the solvating power of the esters themselves (Riedel et al., 2013). Both ethyl and butyl acetate are "recommended" solvents, and all the solvent selection guides published so far agree with attributing low health and environmental scores (not problematic compounds) to the entire ester class (Henderson et al., 2011; Prat et al., 2014, 2016).

\section{Carbonates}

Linear and cyclic carbonates are probably among the most eco-friendly alternatives to halogenated solvents that could be applied for the extraction of PHA and PHB (the latter usually more difficult to be extracted due to its higher crystallinity and lower solubility in organic solvents), allowing the recovery of biopolymers with good properties. Dimethyl carbonate (DMC) is an example of green (it is fully biodegradable, minimally toxic for the operators and the environment) and well-performing solvent (Samorì et al., 2015a,b): DMC resulted highly efficient in terms of extraction yields, polymer purity, and polymer molecular weight, with the additional benefit of being applied directly on wet biomass. Also, 1,2-propylene carbonate (PC) and ethylene carbonate (EC), two solvents with low toxicity and therefore potentially usable in many human-related applications including cosmetics, give good results (Fiorese et al., 2009; Aramvash et al., 2018); it has been observed a decrease in the molecular weight by increasing the temperature for both solvents, probably due to a collateral reaction between the carbonate and the esters in the polymer. This suggests setting the boiling point as a limit temperature for the extraction. Despite being fewer common solvents used in industrial processes than esters and alcohols, DMC, PC, and EC are also included in the most recent solvent selection guides (Prat et al., 2016): among these polar aprotic solvents, DMC seems the greenest carbonates (ranking "recommended" because it does not have any H3xx statements after full REACh registration) and thus indicated as a potential replacement for various ketones and esters.

\section{Ketones}

Among ketones, only the extraction method performed by Koller et al. (2013) with acetone at high temperature and pressure $\left(120^{\circ} \mathrm{C}, 7\right.$ bar) gave a polymer with high molecular weight $(1.0 \mathrm{MDa})$ and PDI of 1.5 , easily recoverable by cooling the solution at $4^{\circ} \mathrm{C}$ without the addition of an anti-solvent. All the other conditions/ketones work generally well in terms of recovery and purity but providing short chain length PHA. The temperature at which the extraction is performed results detrimental for recovering PHA from inside the cellular matrix: for example, cyclohexanone recovers only $16 \%$ of the polymer at $80^{\circ} \mathrm{C}$ (even after $20 \mathrm{~h}$ ) but more than $99 \%$ within 3 min if the temperature is increased at $120^{\circ} \mathrm{C}$ (Jiang et al., 2018). In general, the ketone family has a worse profile than alcohols or esters: despite ranked as "recommended," acetone generates VOCs, but is not toxic and readily biodegradable, whereas cyclohexanone was ranked as "problematic," given that its synthesis via benzene and cyclohexane is not considered as sustainable (Henderson et al., 2011; Prat et al., 2014, 2016).

\section{Other Solvents}

Various aprotic solvents like anisole, DMSO, and DMF have been used to extract PHA from single strains. Anisole is probably the most interesting for application in a large-scale plant: PHA extraction and purity yields are over 96\% (Rosengart et al., 2015), and it is ranked "recommended" since it does not have any $\mathrm{H} 3 \mathrm{xx}$ (health hazard) or H4xx (acute environmental toxicity or bio-accumulation potential) statements (Prat et al., 2016); however, analogously to DMSO and DMF, polymer recovery has to be accomplished using an anti-solvent like ethanol, due to the boiling point above $150^{\circ} \mathrm{C}$ of all of them. A similar concept must be applied if non-volatile solvents like ionic liquids (IL) are used: these solvents (e.g., 1-ethyl-3-methylimidazolium diethylor dimethylphosphate) are capable of interacting with bacterial cell wall components like peptidoglycan and phospholipids via intermolecular $\mathrm{H}$-bonds or electrostatic interactions, dissolving the NPCM and suspending PHA stored inside the cells. But since they are not removable under vacuum due to their negligible vapor pressure, alcohols are required as anti-solvents to precipitate $\mathrm{PHA}$ or purifying $\mathrm{PHA}$ after filtration (even if filtrating IL's solution needs large porosity filters because of the intrinsic high viscosity of the solution); contrarily to what happens with high-boiling point solvents like anisole, the purity of the extracted PHA is low (from 30 to $86 \%$ if filtration or precipitation are applied, respectively) (Kobayashi et al., 2015; Dubey et al., 2018; Koller, 2020). For these reasons (low purity and "PHA-suspension" effect) the use of ILs seems more a pretreatment than a real extraction, oriented to disaggregate the 
cellular components and then facilitate the action of an organic solvent capable of solubilizing PHA.

In summary, the use of solvents for the extraction of PHA from pure cultures is effective as it generally allows the extraction of PHAs with recovery yield up to $90-99 \%$ and purity yield up to $89-100 \%$. The factors that influence mostly the extraction yields are:

- the temperature of the process, generally pivotal for increasing the solubility of PHA in the organic solvent and thus increasing the recovery efficiency;

- the nature of the polyester included inside the bacteria, being co-polymers easier to be extracted than homopolymers, especially in the case of a high percentage of monomers longer than hydroxybutyrate due to better solubility in organic solvents and a lower crystallinity,

- the amount of the polyester included inside the bacteria, since a higher number of PHA granules can exert a tensile strength on bacterial cell wall and membranes,

- the presence of water around bacterial cells (extraction of wet biomass), that can both create a barrier around the cells preventing the access of the solvent to the polymer and hydrolyze solvents (e.g., esters).

One of the main limitations in the use of solvents to extract PHA from bacterial cells relies on the need of separating the polymer from the solvent once it has been extracted; this can be done by solvent evaporation or by using an anti-solvent in which PHA is not soluble, but in both cases, a quite relevant amount of energy has to be applied. Another limitation common to both halogenated and non-halogenated solvents is the fact that a high solvent-to-biomass ratio must be used in the extraction process (up to a 20 -fold mass of the microbial biomass) (Koller et al., 2013), and this is especially true for some "super-solvents." These solvents (e.g., chloroform, $\gamma$-valerolactone, ethyl lactate, DMC) show an excellent affinity for PHA, are capable to give a concentrated liquid solution of PHA at high temperature but they become a jelly-phase (solvent entrapped in the extracted PHA) once they are at rt (Samorì et al., 2015b, 2016; Prati et al., 2019). For keeping the solutions of "super solvents" and high amounts of extracted PHA (necessary for biomass-solvent separation) as liquid, an even higher solvent-to-biomass ratio must be used. It has been claimed that the use of Soxhlet apparatus could contribute to reduce the amount of solvent necessary to achieve a satisfactory PHA recovery on a laboratory scale (Koller et al., 2013), since Soxhlet extraction is operationally a continuous-discrete technique (the solvent acts stepwise but it is also recirculated through the sample, so the system operates both in a continuous manner and as a batch system, De Castro and Priego-Capote, 2010). Some comparisons between Soxhlet extraction and direct extraction in a batch-mode underline that the PHA recovery from bacterial biomass can be higher (1.31.8 -fold) if the first approach is applied with specific solvents like acetone, hexane, and chlorinated compounds (Jiang et al., 2006; Manangan and Shawaphun, 2010; Lupescu et al., 2016). However, a not uniform effect on the molecular weight of the recovered polymer has been observed: since bacterial samples are extracted at the solvent boiling point over long periods, thermal decomposition of thermolabile target species can occur (De Castro and Priego-Capote, 2010), especially with some solvents like chloroform (Ramsay et al., 1994), and DMC (Samorì et al., 2015a). Other solvents like acetone (Jiang et al., 2006) do not behave in this way, and no significant change in the molecular weight is observed during the Soxhlet extraction process, confirming that the temperature conditions are not in a range in which random chain-end scission can occur (Koller et al., 2013).

To the best of our knowledge, no continuous extraction protocols (e.g., countercurrent extraction or flow processes) have been applied for recovering PHA, nor at a lab-scale neither at higher TRL. However, this approach is described as the best way to obtain requirements of high safety (small volume of solvents being processed at any given time, through the elimination of large reactors), low waste generation, and energy efficiency (improvements in mixing and heating) on a large scale, pillars of the Green Chemistry and Green Engineering philosophy (Newman and Jensen, 2013). The application of continuous extraction with green solvents like carbonates, esters, and ketones capable to recover polymers with high molecular weight (1.11.4 MDa) and stable PDI (1.4-3.9) on a lab-scale, could be a suitable and more sustainable alternative to halogenated compounds in a scale-up perspective (Righi et al., 2017; Vogli et al., 2020).

\section{Cellular Lysis Methods Applied to Single Microbial Strains}

The solubilization of non-PHA cellular material (NPCM) that surrounds PHA granules is an alternative approach to recover PHAs. The substances used for this purpose are oxidants like sodium hypochlorite $(\mathrm{NaClO})$, alkaline or acid compounds, and surfactants (Table 2), or enzymes (Table 3).

\section{Oxidants}

$\mathrm{NaClO}$ is a strong oxidizing chemical able to degrade proteins, lipids, carbohydrates, and nucleic acids that constitute the nonPHA matter, thus enhancing their solubilization in aqueous solutions. Although PHA with a purity up to $99 \%$ and a recovery yield over $80 \%$ can be obtained (Heinrich et al., 2012; LópezAbelairas et al., 2015), the treatment with this salt drastically reduces the molecular weight of the polymer. A high amount of $\mathrm{NaClO}$ solution is usually required, making this method appropriate only to enhance recovery yield (Hahn et al., 1993). Besides, the application of $\mathrm{NaClO}$ for NCPM digestion always bears the risk of formation of toxic halogenated compounds, and it appears rather difficult to completely remove $\mathrm{NaClO}$ traces from the recovered PHA (Koller et al., 2013).

\section{Alkaline and Acid Compounds}

Sodium hydroxide $(\mathrm{NaOH})$ and potassium hydroxide $(\mathrm{KOH})$ are milder digestion agents that cause saponification of the lipids present in the cell wall of microorganisms, increasing membrane permeability and helping the release of proteins and non-PHA material (Kosseva and Rusbandi, 2018). This kind of treatment provides a very high polymer recovery and 
TABLE 2 | PHAs extraction from single strains through cellular lysis assisted by chemicals.

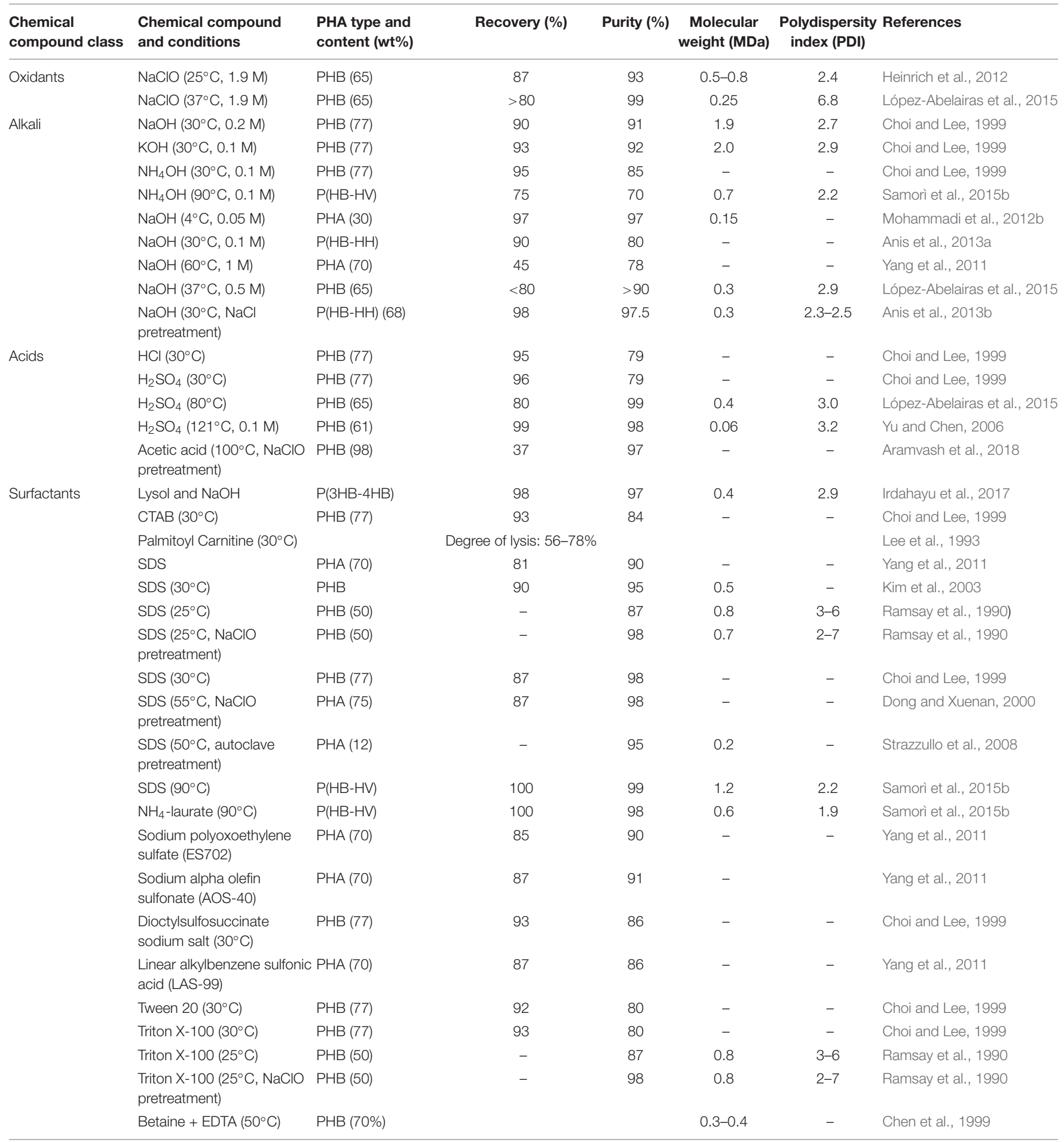

The investigated parameters are the chemicals used for the cellular lysis, the initial content of PHA in bacteria (wt\% by dry weight) and the recovery (\%), and the properties of the extracted PHA (purity\%, molecular weight in MDa and polydispersity index).

purity (above 90\%), even under relatively mild conditions (0.1-0.2 $\mathrm{M}$ at $\left.30^{\circ} \mathrm{C}\right)$; more important, the molecular weight of the extracted PHA seems to be not affected by alkali, being around 1.9-2.0 $\mathrm{MDa}$ with a polydispersity of 2.70-2.90 (Choi and Lee, 1999), probably due to the limited digestion time $(1 \mathrm{~h})$ performed at low temperature $\left(30^{\circ} \mathrm{C}\right)$ (Mannina et al., 2020). In the literature, various acids like $\mathrm{H}_{2} \mathrm{SO}_{4}$ or $\mathrm{HCl}$ were studied for PHAs recovery, providing high recoveries (above $90 \%$ ), purity (up to $99 \%$ ) but low molecular weight (around 0.06 MDa) (Yu and Chen, 2006). Furthermore, the 
TABLE 3 | PHAs extraction from single strains through cellular lysis assisted by enzymes.

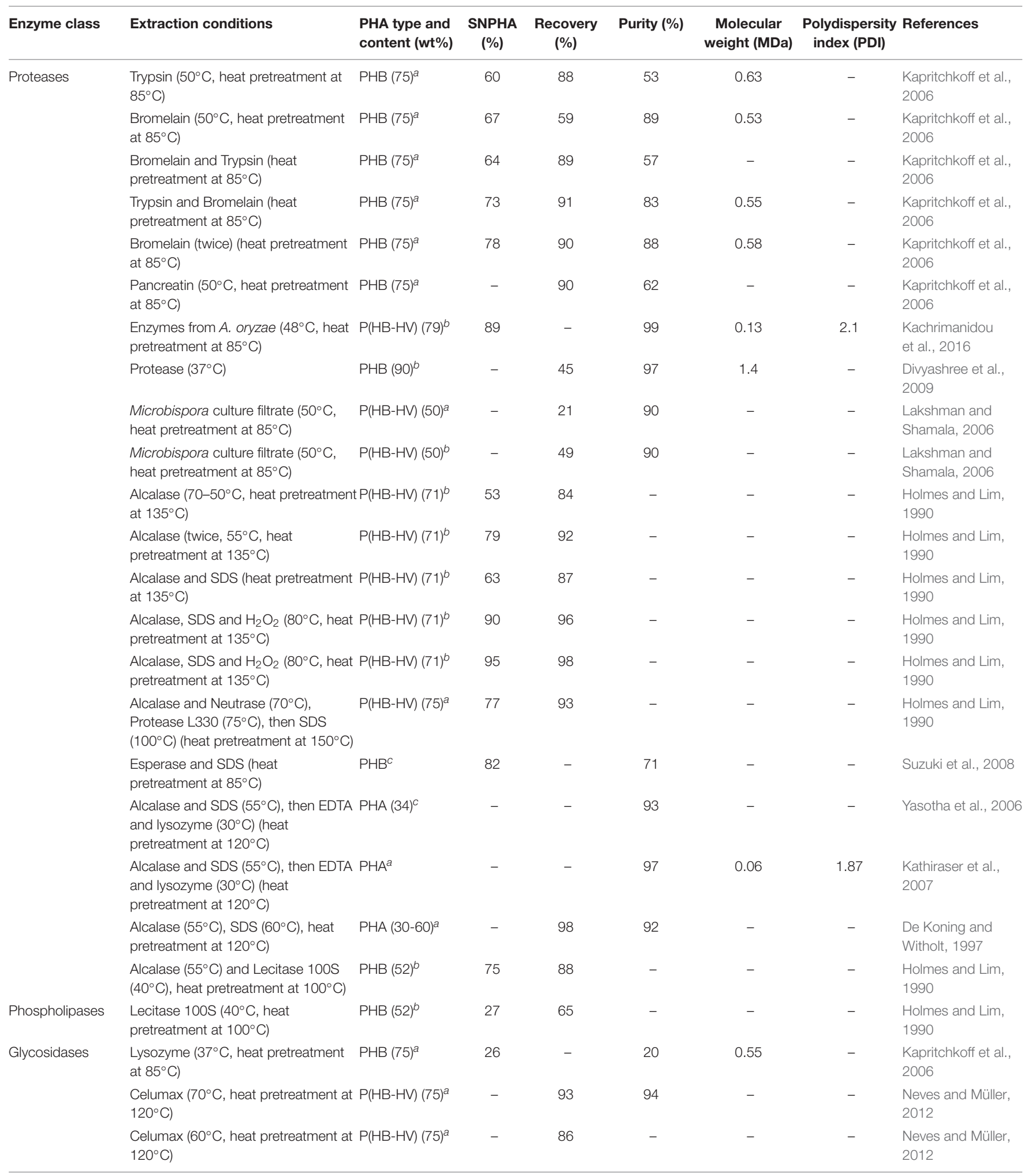

The investigated parameters are the enzymes used for the cellular lysis, the initial content of PHA in bacteria (wt\% by dry weight), the non-PHA biomass solubilization (SNPHA) and the recovery (\%), and the properties of the extracted PHA (purity\%, molecular weight in MDa and polydispersity index).

aPHA recovered by solvent extraction.

${ }^{b}$ PHA recovered by centrifugation.

${ }^{c}$ PHA recovered by ultrafiltration/diafiltration. 
potential hazard and corrosivity of these chemicals cause risks for the operators when they are used in high concentrations, making their use inappropriate for industrial applications (Yu and Chen, 2006).

\section{Surfactants}

Surfactants' mode of action is based on first incorporation into the lipidic bilayer of cell membranes, followed by an increase of the cellular volume until the membrane breaks to produce large micelles of surfactant and phospholipids. This finally causes the PHA release (Pérez-Rivero et al., 2019). Furthermore, surfactants can solubilize proteins and other non-PHA cellular material facilitating the disruption of cell membranes (Mannina et al., 2020). Anionic surfactants like sodium dodecyl sulfate (SDS) or alkylbenzene sulfonates (LAS) are the most used surfactants, tested alone or in combination with chemical or thermal pretreatments; however, SDS seems to give random results in terms of recovery, purity, molecular weight, and polydispersity index, and it is not easy to attribute its real effect on all of these parameters. Cationic surfactants like benzalkonium chlorides (BAC), palmitoyl carnitine, or hexadecyltrimethylammonium bromide $(\mathrm{CTAB})$ are less used compounds than anionic ones and seem to decrease the molecular weight of the recovered polymer (despite the purity and the recovery are similar). Nonionic surfactants like Triton X-100 or Tween-20 perform well in terms of polymer recovery, polymer purity, and molecular weight of the recovered polymer.

Surfactants are often combined with $\mathrm{NaOH}, \mathrm{NaClO}$, and chelating agents to increase the purity and recovery yield of the extracted polymer (Ramsay et al., 1990; Dong and Xuenan, 2000). Degradation of polymer granules and therefore reduction of molecular weight can generally occur only if high temperatures or $\mathrm{pH}$ are used (Kunasundari and Sudesh, 2011). The main limitation of this approach is the high dosage of highly watersoluble surfactants that have to be used for achieving satisfactory PHA recovery; this results in high costs of recovery and treatment of wastewater (Kapritchkoff et al., 2006). To overcome this drawback, the application of recoverable and recyclable surfactants can bring an overall improvement of the process, both in terms of economics and environmental footprint; for example, Switchable Anionic Surfactants (SAS) are compounds whose water solubility can be tuned by the addition and removal of $\mathrm{CO}_{2}$ (Samorì et al., 2015b): cellular lysis is accomplished by using the water-soluble (ionic) form of the surfactant, whereas the recovery (more than 90\%) of the surfactant in its non-ionic form is achievable by changing the $\mathrm{pH}$ of the aqueous solution using $\mathrm{CO}_{2}$. In this way, even if high doses of surfactants are necessary to achieve an excellent polymer recovery, the surfactant can be completely recycled.

\section{Enzymes}

Specific enzymes like proteases and glycosidases can be applied to PHA-producing bacteria to hydrolyze peptide or glycosidic bonds of microbial proteins and carbohydrates/complex carbohydrates (e.g., glycoproteins and glycolipids), respectively. Alcalase (subtilisin A) is one of the most used proteases applied for PHA recovery, thanks to very broad substrate specificity and a good tolerance toward a quite large working temperature range $\left(45-65^{\circ} \mathrm{C}\right)$; it usually provides recoveries above $90 \%$. Other proteases like Trypsin and Bromelain work well in terms of polymer recovery (around 90\%) and molecular weight (0.5$0.6 \mathrm{MDa}$ ); the non-PHA biomass solubilization (SNPHA) is generally higher with this class of enzymes than with glycosidases or phospholipases, ranging between $53-95 \%$ vs. about $26 \%$. To increase the extraction efficiency, cocktails of proteases, nucleases, phospholipases, lysozymes, and other enzymes, in combination with surfactants and chelating agents can be applied. Centrifugation and use of solvents are the most employed extraction method but ultrafiltration and diafiltration are also applied (Kapritchkoff et al., 2006; Kathiraser et al., 2007); if the purity of the recovered polymer is similar, simple centrifugation seems to provide higher recovery than the use of organic solvents (Lakshman and Shamala, 2006).

In summary, enzymatic processes allow extraction of PHA with a wide range of purity (up to $88.8-97 \%$ ) because the enzyme lysis effect is strictly related to reactions they catalyze. However, the process is expensive due to the high cost of enzymes and the complexity of the extraction process (Patel et al., 2009).

An alternative cell lysis approach recently described to recover PHA from single strains exploits whole microorganisms as cell-lytic agents (namely predatory bacteria of other Gram-negative bacteria), instead of isolated enzymes (Koller, 2020); these predatory bacteria (e.g., the species Bdellovibrio bacteriovorus) have a hydrolytic arsenal (e.g., extracellular-like PHA depolymerase) capable of breaking the cell walls of the prey (the culture of PHA-producing bacteria) in a relatively short time frame (24 h of "predation"), causing the release of the intracellular PHA in the culture medium (Martínez et al., 2016). To avoid the further hydrolysis of the released PHA granules by extracellular-like PHA depolymerase (that can hydrolyze up to $80 \%$ of the PHA produced by the prey), engineering of the predator seems to be the method of choice (Martínez et al., 2016). This process has been proposed as robust and generalizable since applicable to prey upon a wide range of Gram-negative bacteria, however, it is worth mentioning that high PHA purity values can be achieved just after extraction of the co-culture's sediments with chlorinated solvents. A strictly related approach (even if on a longer time frame) is the use of some animals like the mealworm Tenebrio molitor (Murugan et al., 2016) or rats (Kunasundari et al., 2013; Ong et al., 2018) to digest the NPCM of PHA-producing bacteria and excrete PHA granules with a high purity level, intact molecular weight and native morphology. Even in this case, PHA must be separated from the fecal pellets with chemicals (e.g., alkaline water), thus these approaches could be considered as lowcost and sustainable pre-treatments instead of self-sustaining recovery methods.

\section{EXTRACTION OF PHA FROM MIXED MICROBIAL CULTURES}

Mixed microbial cultures (MMC), able to accumulate intracellular PHA similarly to what occurs with single strains 
and with comparable production rates, are probably the new frontier in the field of marketable PHA production, especially if this activity is coupled with wastewater treatment for reducing the cost of raw material and energy consumption aspects (Dias et al., 2006; Jiang et al., 2018). However, MMC downstream costs can be even more impacting on the overall process than single strain downstream costs especially because of a more challenging PHA extraction phase (Patel et al., 2009; Samorì et al., 2015a) and the difficulty in extracting PHA from MMC can be reflected both in terms of polymer recovery and purity (Mannina et al., 2019).

\section{Solvent Extraction Methods Applied to Mixed Microbial Cultures Halogenated Solvents}

Chloroform and dichloromethane are the most used solvents applied so far in the extraction of PHA from MMC (Table 4). In some cases, an acetone pre-treatment was used to enhance cell breakage and improve the recovery of PHA (Serafim et al., 2008b); PHA recovery is usually achieved by solvent evaporation or by polymer precipitation with water, alcohols (methanol and ethanol) or cold petroleum ether. Occasionally a subsequent purification step, which consists of a washing step with acetone and diethyl ether, has been applied.

Patel et al. (2009) obtained an 'ultra-high molecular weight PHAs' (2-3 MDa) with a very narrow size distribution (PDI of 1.3) by applying dichloromethane; however, the recovery was very low (18-30\%), suggesting that such a low result could be due to the presence of a PHA "difficult to be extracted" or to the presence of extracellular biomass matrix in which the PHA containing cells are embedded (Patel et al., 2009). This observation was confirmed by Samorì et al. (2015a), with a polymer recovery of $52 \%$, a polymer molecular weight of 1.4 $\mathrm{MDa}$, and a polydispersity of 2.0. Generally, chloroform allows the recovery of polymers with a lower molecular weight if compared to dichloromethane (Serafim et al., 2008b) (Table 4).

\section{Halogen-Free Solvents}

The use of non-conventional solvents for extracting PHA from MMC is not so well documented as in the case of single strains; in particular, the presence of longer co-monomers than $3 \mathrm{HB}$ can influence the extraction thanks to a change in the polarity and the crystallinity of the polymer (Laycock et al., 2014).

Alcohols like butanol and ketones like acetone allowed the recovery of PHAs with a purity up to $98 \%$ but the molecular weight dropped to $0.2-0.6 \mathrm{MDa}$ with a polydispersity of $1.7-3.4$ (Laycock et al., 2014).

Carbonates like dimethyl carbonate provide a recovery percentage of about $60 \%$ over two cycles, with a molecular weight above $1 \mathrm{MDa}$ and a high purity level (98\%) (Samorì et al., 2015a). If a $\mathrm{NaClO}$ pre-treatment is coupled to DMC extraction, the overall recovery process increases up to $82 \%$ but the molecular weight drops down by five times $(0.2 \mathrm{MDa})$ : reaction time and temperature of this chemical pre-treatment strongly influence the molecular weight of the recovered polymers because of the oxidizing properties and nucleophilicity of $\mathrm{NaClO}$. The degrading effect on the polyesters is also emphasized by the increase in the PDI values, a sign of the polymer chains shortening due to some random chain scission.

\section{Cellular Lysis Methods Applied to Mixed Microbial Cultures}

The chemicals mainly used for the extraction of PHA from MMC through cellular lysis are oxidants, alkali, and surfactants, similarly to what is usually applied to single strains (Table 5). On the other hand, the use of enzymes to solubilize the non-PHA cellular matrix is not reported, presumably because the enzymatic digestion is "too mild" for the high cellular resistance of MMC.

\section{Oxidants}

Analogously to single strains (see section "Cellular lysis methods applied to single microbial strains"), $\mathrm{NaClO}$ can degrade most of the NPCM (it becomes water-soluble when oxidized) of MMC, while the PHA granules can be easily separated by precipitation (Mannina et al., 2020). However, also in this case, the treatment with $\mathrm{NaClO}$ can affect the quality of the obtained PHA (in terms of purity, polydispersity index, and molecular weight), compromising the final polymer applications (Kunasundari and Sudesh, 2011; Samorì et al., 2015a; Mannina et al., 2019). Villano et al. (2014) treated MMC with $\mathrm{NaClO}$ for 3 and $24 \mathrm{~h}$ at rt and noticed that the effect of $\mathrm{NaClO}$ on the purity and the molecular weight of the extracted polymer is similar regardless of the reaction time; on the other hand, the temperature of the $\mathrm{NaClO}$ treatment inversely impacts both the recovery and the polydispersity index: the PHA recovery decreases from rt (100\%) to $85^{\circ} \mathrm{C}(50 \%)$, whereas the polydispersity index increases (giving more heterogeneous polymers) if the treatment is performed at high temperature (values around 3) or rt (values of 4-10) (Table 5). Recently, Lorini et al. (2020) investigated the impact of two stabilization protocols applied at the end of the accumulation phase (thermal drying at $145^{\circ} \mathrm{C}$ for $30 \mathrm{~min}$ and at $70^{\circ} \mathrm{C}$ overnight, and wet acidification with $\mathrm{H}_{2} \mathrm{SO}_{4}$ ) in combination with $\mathrm{NaClO}$ digestion (at rt overnight) for preserving the amount and the length of PHA produced by MMC. A wet-acidification pretreatment provides three-times higher molecular weights $(0.4 \mathrm{MDa})$ than a thermal pre-treatment, a recovery of $96 \%$, and a polymer purity of $90 \%$.

\section{Alkaline Compounds}

According to Jiang et al. (2015), alkaline treatments cause PHA hydrolysis and the consequent decline of the molecular weight (generally between 0.3 and $0.5 \mathrm{MDa}$ ) and increase of the polydispersity index, but if a pretreatment like freezedrying has applied this phenomenon is mitigated. A possible explanation relies on the fact that PHA crystallization can increase the resistance toward chemical treatments induced either by complete removal of water or by damaging the cell membrane through surfactants (Jiang et al., 2015). Among the tested alkaline compounds, $\mathrm{NaOH}$ gives higher PHA recovery, purity, and molecular weight than $\mathrm{NH}_{4} \mathrm{OH}$, but also higher polydispersity index values (4-10 vs. 2-3) (Jiang et al., 2015; Mannina et al., 2019). However, $\mathrm{NH}_{4} \mathrm{OH}$ could be a better 
TABLE 4 | PHAs extraction from mixed microbial cultures with solvents.

\begin{tabular}{|c|c|c|c|c|c|c|c|}
\hline Solvent class & $\begin{array}{l}\text { Solvent type and } \\
\text { extraction conditions }\end{array}$ & $\begin{array}{l}\text { PHA type and } \\
\text { content (wt } \%)\end{array}$ & Recovery (\%) & Purity (\%) & $\begin{array}{c}\text { Molecular } \\
\text { weight (MDa) }\end{array}$ & $\begin{array}{l}\text { Polydispersity } \\
\text { index (PDI) }\end{array}$ & References \\
\hline \multirow{10}{*}{$\begin{array}{l}\text { Halogenated } \\
\text { solvents }\end{array}$} & $\mathrm{CH}_{2} \mathrm{Cl}_{2}\left(50^{\circ}\right)$ & $\mathrm{P}(\mathrm{HB}-\mathrm{HV})(40)$ & 52 & 94 & 1.4 & 2.0 & Samorì et al., 2015a \\
\hline & $\begin{array}{l}\mathrm{CH}_{2} \mathrm{Cl}_{2} \text { (acetone } \\
\text { pretreatment) }\end{array}$ & $\mathrm{P}(\mathrm{HB}-\mathrm{HV})(25)$ & $18-30$ & - & $2-3$ & 1.3 & Patel et al., 2009 \\
\hline & $\mathrm{CH}_{2} \mathrm{Cl}_{2}$ & PHB (72) & 56 & 98 & 1.8 & - & Jiang et al., 2015 \\
\hline & $\mathrm{CHCl}_{3}\left(100^{\circ} \mathrm{C}\right)$ & $\mathrm{PHA}$ & - & - & $0.3-0.9$ & $1.7-3.9$ & Bengtsson et al., 2010 \\
\hline & $\mathrm{CHCl}_{3}\left(100^{\circ} \mathrm{C}\right)$ & $\mathrm{P}(\mathrm{HB}-\mathrm{HV})(25)$ & - & - & $0.3-1.0$ & $1.5-2.5$ & $\begin{array}{l}\text { Morgan-Sagastume } \\
\text { et al., } 2010\end{array}$ \\
\hline & $\mathrm{CHCl}_{3}\left(37^{\circ} \mathrm{C}\right)$ & $\begin{array}{l}\mathrm{P}(\mathrm{HB}-\mathrm{HV}) \\
(65-72)\end{array}$ & - & - & $0.2-0.6$ & $2.3-2.7$ & $\begin{array}{l}\text { Albuquerque et al., } \\
2011\end{array}$ \\
\hline & $\mathrm{CHCl}_{3}$ & $\mathrm{P}(\mathrm{HB}-\mathrm{HV})(28)$ & - & - & $0.1-0.4$ & $2.2-3.7$ & Dai et al., 2007 \\
\hline & $\mathrm{CHCl}_{3}$ & PHB (66) & - & - & $2.1-3.4$ & $1.3-2.2$ & Serafim et al., 2008b \\
\hline & $\begin{array}{l}\mathrm{CHCl}_{3} \text { (reflux, acetone } \\
\text { pretreatment) }\end{array}$ & PHB & - & - & $0.2-0.4$ & $1.2-2.7$ & Hu et al., 2013 \\
\hline & $\begin{array}{l}\mathrm{C}_{2} \mathrm{H}_{4} \mathrm{Cl}_{2}\left(100^{\circ} \mathrm{C}, \mathrm{HCl} \text { and }\right. \\
\text { PrOH })\end{array}$ & PHB (89) & - & - & - & - & Johnson et al., 2009 \\
\hline \multirow[t]{2}{*}{ Alcohols } & Butanol $\left(125^{\circ} \mathrm{C}\right)$ & $\mathrm{P}(\mathrm{HB}-\mathrm{HV})(15)$ & - & $95-98$ & $0.4-0.6$ & $1.8-3.4$ & Laycock et al., 2014 \\
\hline & 2-butanol $\left(125^{\circ} \mathrm{C}\right)$ & PHB (44) & 83 & - & 0.7 & - & Werker et al., 2015 \\
\hline \multirow[t]{6}{*}{ Carbonates } & Dimethyl carbonate $\left(90^{\circ} \mathrm{C}\right)$ & $\mathrm{P}(\mathrm{HB}-\mathrm{HV})(40)$ & 49 & 98 & 1.3 & 1.9 & Samorì et al., 2015a \\
\hline & $\begin{array}{l}\text { Dimethyl carbonate } \\
\text { (soxhlet) }\end{array}$ & $\mathrm{P}(\mathrm{HB}-\mathrm{HV})(40)$ & 41 & 87 & 0.5 & 2.9 & Samorì et al., 2015a \\
\hline & $\begin{array}{l}\text { Dimethyl carbonate }\left(90^{\circ} \mathrm{C} \text {, }\right. \\
\mathrm{NaClO} \text { pretreatment for } \\
\left.5 \mathrm{~min} \text { at } 100^{\circ} \mathrm{C}\right)\end{array}$ & $\mathrm{P}(\mathrm{HB}-\mathrm{HV})(40)$ & 72 & 89 & 0.5 & 2.8 & Samorì et al., 2015a \\
\hline & $\begin{array}{l}\text { Dimethyl carbonate }\left(90^{\circ} \mathrm{C} \text {, }\right. \\
\mathrm{NaClO} \text { pretreatment for } \\
\left.15 \text { min at } 100^{\circ} \mathrm{C}\right)\end{array}$ & $\mathrm{P}(\mathrm{HB}-\mathrm{HV})(40)$ & 72 & 92 & 0.5 & 2.4 & Samorì et al., 2015b \\
\hline & $\begin{array}{l}\text { Dimethyl carbonate }\left(90^{\circ} \mathrm{C} \text {, }\right. \\
\mathrm{NaClO} \text { pretreatment for } 1 \mathrm{~h} \\
\left.\text { at } 100^{\circ} \mathrm{C}\right)\end{array}$ & $\mathrm{P}(\mathrm{HB}-\mathrm{HV})(40)$ & 82 & 93 & 0.2 & 2.5 & Samorì et al., 2015a \\
\hline & $\begin{array}{l}\text { Dimethyl carbonate }\left(90^{\circ} \mathrm{C} \text {, }\right. \\
\text { twice) }\end{array}$ & $\mathrm{P}(\mathrm{HB}-\mathrm{HV})(40)$ & 12 & 95 & 1.2 & 2.7 & Samorì et al., 2015a \\
\hline \multirow[t]{3}{*}{ Ketones } & Acetone $\left(125^{\circ} \mathrm{C}\right)$ & $\mathrm{P}(\mathrm{HB}-\mathrm{HV})(15)$ & - & $95-98$ & $0.4-0.6$ & $1.9-3.4$ & $\begin{array}{l}\text { Arcos-Hernández et al., } \\
2013\end{array}$ \\
\hline & Acetone $\left(125^{\circ} \mathrm{C}\right)$ & $\mathrm{P}(\mathrm{HB}-\mathrm{HV})(15)$ & - & $95-99$ & $0.5-0.6$ & $1.9-3.0$ & Laycock et al., 2014 \\
\hline & Acetone $\left(125^{\circ} \mathrm{C}\right)$ & $\mathrm{P}(\mathrm{HB}-\mathrm{HV})$ & 51 & $75-98$ & $0.2-0.6$ & $1.7 \pm 0.1$ & Chan et al., 2017 \\
\hline
\end{tabular}

The investigated parameters are the solvents used for the extraction, the initial content of PHA in bacteria (wt\% by dry weight) and the recovery (\%), and the properties of the extracted PHA (purity\%, molecular weight in MDa and polydispersity index). 
TABLE 5 | PHAs extraction from mixed microbial cultures through cellular lysis assisted by chemicals.

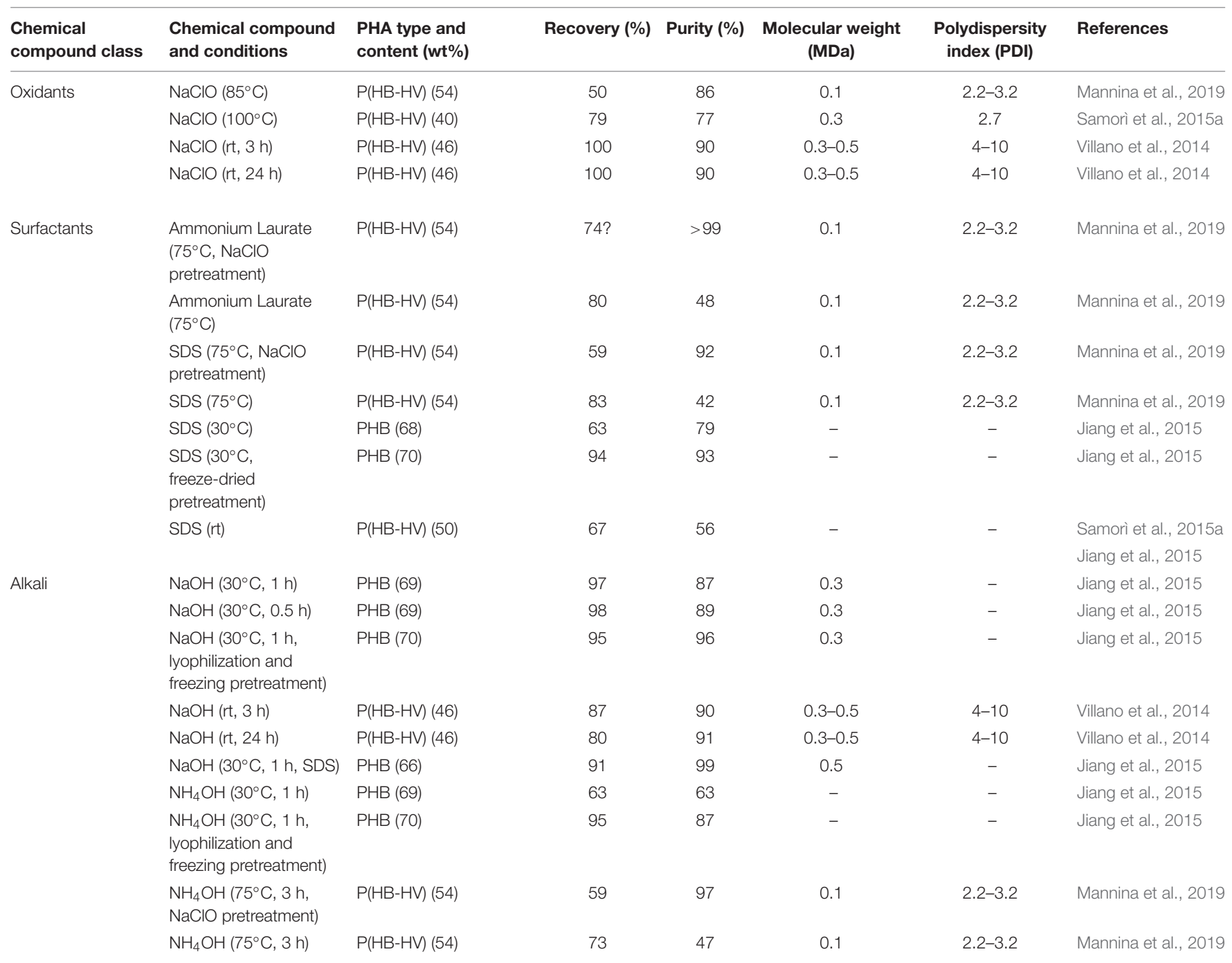

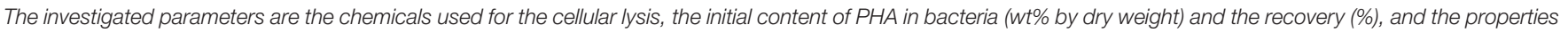
of the extracted PHA (purity\%, molecular weight in MDa and polydispersity index).

alternative than $\mathrm{NaOH}$ since it is claimed to be potentially easier to be recycled (Mannina et al., 2019); additionally, $\mathrm{NH}_{4} \mathrm{OH}$ performances can be improved by applying specific pretreatments (Jiang et al., 2015): if a $\mathrm{NaClO}$ pretreatment is applied, the polymer purity increases, whereas if a freezedrying pretreatment is applied the polymer recovery increases (Table 5). Recently Burniol-Figols et al. (2020) investigated the effect of $\mathrm{NH}_{4} \mathrm{OH}$ on PHA purity, recovery, and molecular weight: long incubation times and high $\mathrm{NH}_{4} \mathrm{OH}$ concentrations negatively impact the polymer recovery but have no influence on its purity, whereas increasing the temperature of the digestion both purity and recovery increase. However, even if at $140^{\circ} \mathrm{C}$ the highest recovery and purity is achieved (90 and $83 \%$, respectively), a drastic reduction of the molecular weight is also observed (from $0.6 \mathrm{MDa}$ at $30^{\circ} \mathrm{C}$ to $0.08 \mathrm{MDa}$ at $140^{\circ} \mathrm{C}$ ), suggesting an optimal temperature range of $75-$ $115^{\circ} \mathrm{C}$ to get high recovery of PHA (above 90\%) and maintaining the molecular weight of PHA at reasonable values (0.2 $\mathrm{MDa})$.

A direct comparison between $\mathrm{NaOH}$ and $\mathrm{NaClO}$ treatments underlines that $\mathrm{NaClO}$ works better under the same conditions (Villano et al., 2014) and the $\mathrm{PHA}$ recovered using $\mathrm{NaClO}$ is more thermally stable (up to $200^{\circ} \mathrm{C}$ ) than that recovered by $\mathrm{NaOH}$ (between $\mathrm{rt}$ and $100^{\circ} \mathrm{C}$ ) (Laycock et al., 2014).

\section{Surfactants}

Surfactants seem to be an effective way to extract PHA with good purity and in a satisfactory amount just in combination with specific pre-treatments (Table 5). For example, if SDS or ammonium laurate are applied alone, purity values of $40-60 \%$ are obtained, whereas if $\mathrm{NaClO}$ or freeze-drying are applied as pre-treatments before the use of the surfactant, this parameter increases up to $90 \%$. However, surfactants have an impact on PHAs molecular weight (around $0.1 \mathrm{MDa}$ ), independently by 
the pre-treatment (Mannina et al., 2019). Furthermore, a high surfactant to biomass ratio is usually required, and consequently, the surfactant recovery generates a large quantity of wastewater that has to be treated (Jacquel et al., 2008); for overcoming this issue, as for single strains, recyclable surfactants like Switchable Anionic Surfactant (SAS) have been applied on MMC by Mannina et al. (2019): ammonium laurate gives a polymer purity of $48 \%$, improvable by a pre-treatment with $\mathrm{NaClO}$ $(100 \%)$. Also in this case, the molecular weight of extracted polymers is quite low $(0.1 \mathrm{MDa})$ and the polydispersity is $2.2-$ 3.2 (Mannina et al., 2019) (Table 5), but the surfactant proved to be completely recyclable.

\section{OVERALL COMPARISON BETWEEN THE TWO EXTRACTION APPROACHES}

The overview of the available extraction methods reported in Tables 1-5 allows a comparison of the performance on single strains and mixed microbial cultures in terms of the overall efficiency of the process of PHA recovery.

\section{Recovery}

Mean PHB or PHA recoveries reported in the literature through solvent extraction or cellular lysis from single strains or MMC have been reported in Figures 4, 5.

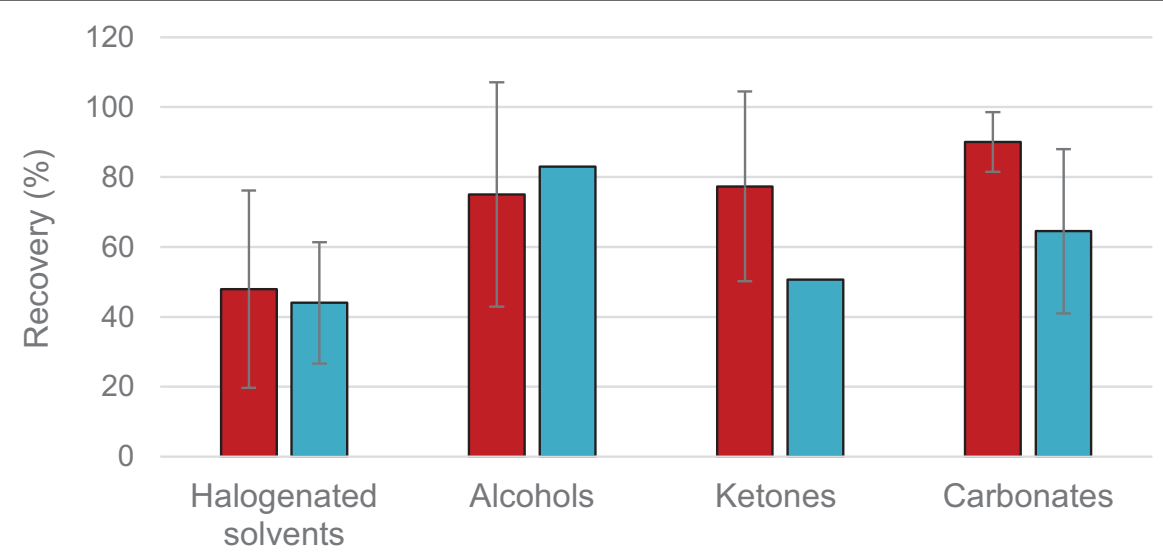

$\square$ Single strains $\square \mathrm{MMC}$

FIGURE 4 | Mean recovery (\%) of PHA extracted with solvents (halogenated solvents, alcohols, ketones, and carbonates) from single strains or MMC.

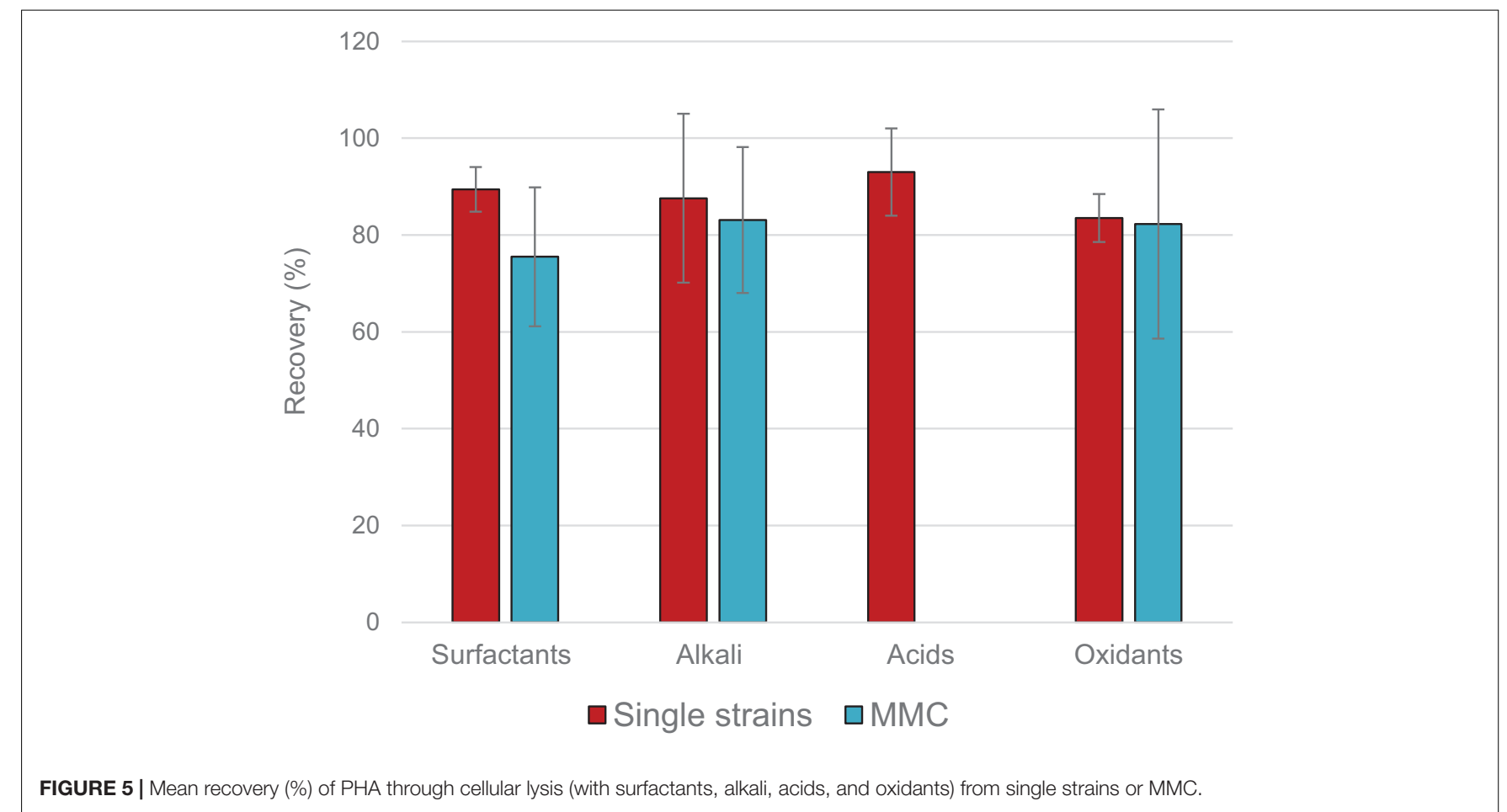




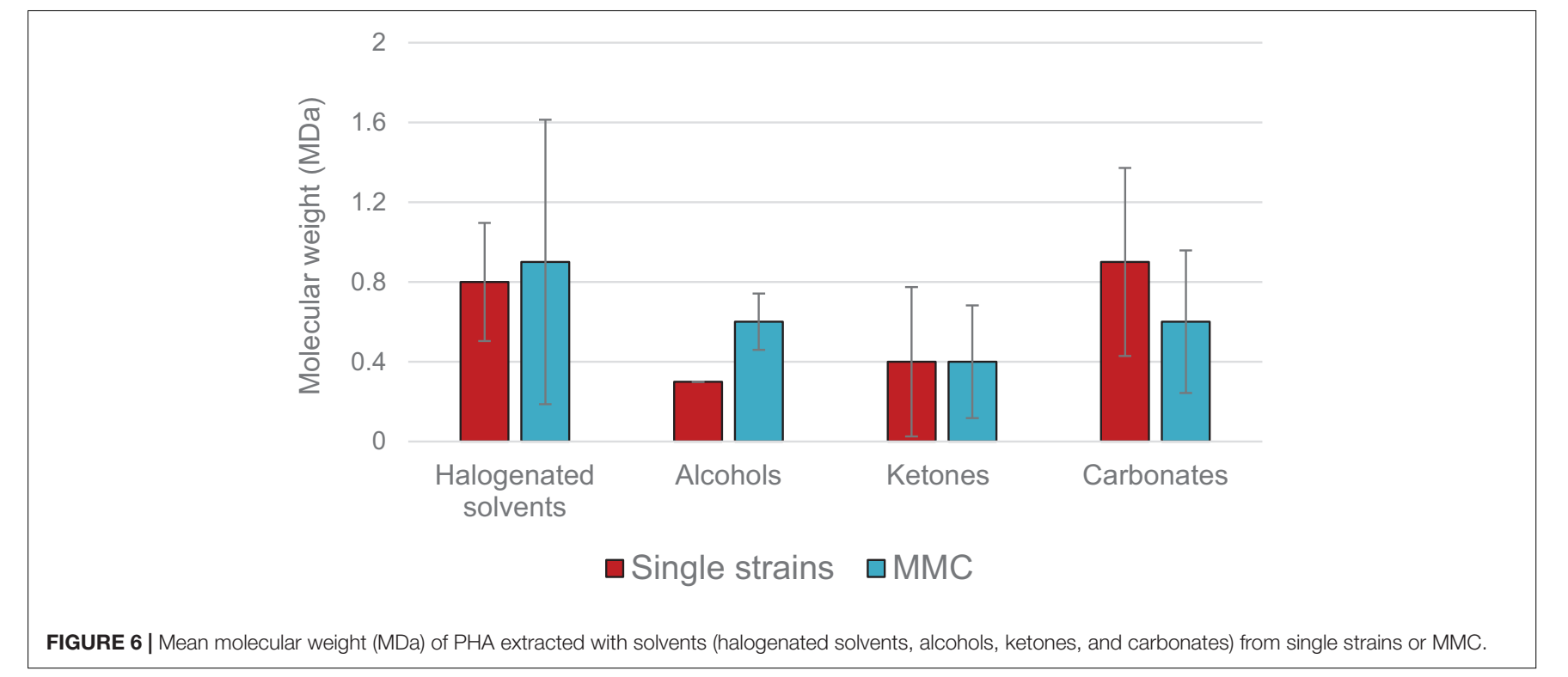

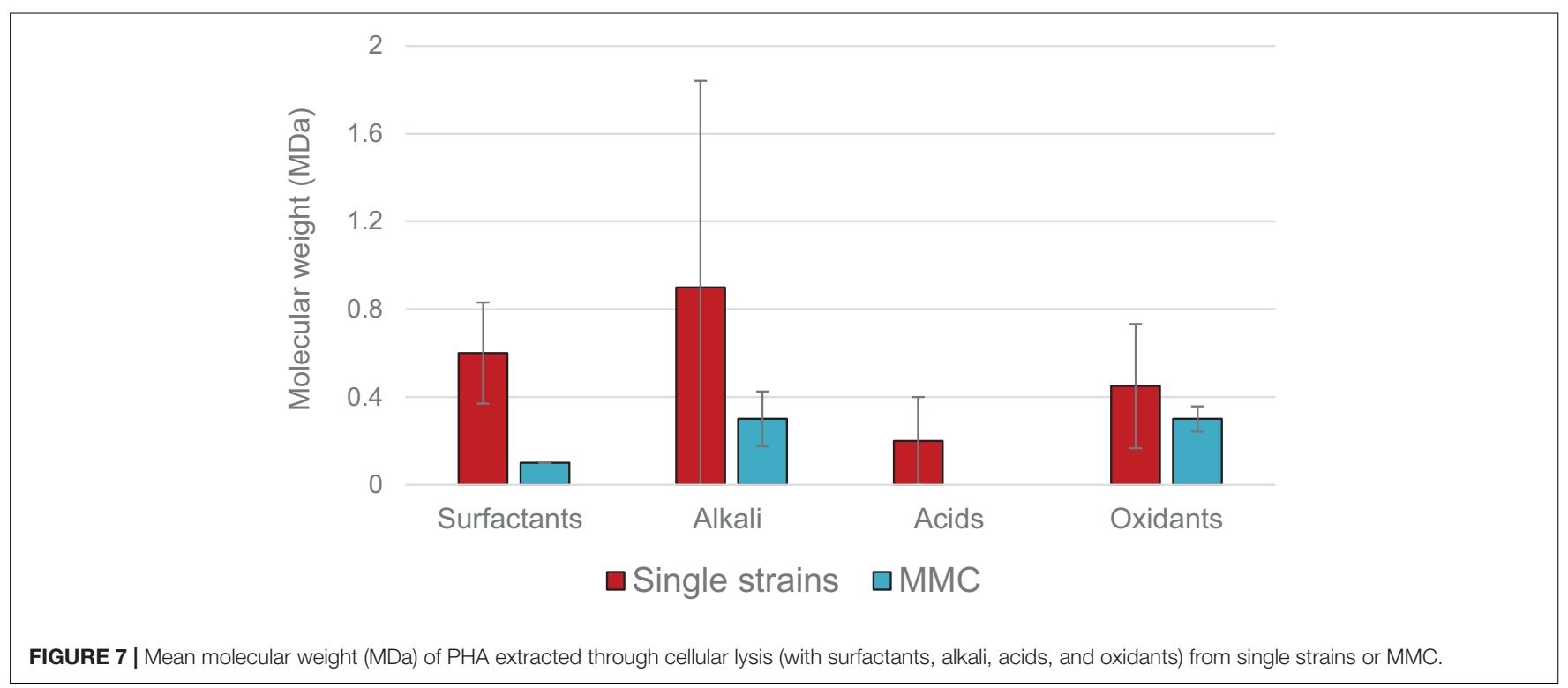

The variability of results expressed here as standard deviations (SD) of all the values reported in the literature (Table 1) is very high, mainly due to the small amount of data related to solvent extraction on MMCs. For almost all solvent classes reported in the literature, PHA recovery is lower when MMC are extracted, confirming that the extraction process is more difficult for MMC than for single strain cultures. MMC are claimed to be more resistant to cell hydrolysis, probably because of a strong extracellular biomass matrix that contains the PHA accumulating cells. Furthermore, Patel et al. (2009) hypothesized a decrease in cellular fragility and therefore a minor amount of solvent able to access polymer granules because of a stronger non-PHA cellular materials (NPCM) and lower initial PHA content which results in a lower cell constrain.
The recovery data achieved from single strains are considerably higher (about 25\%) when ketones or carbonates are applied; however, the literature does not report plenty of data about the extraction of MMC with ketones, therefore more data are needed for a more accurate analysis. The results obtained with halogenated solvents from single strains and mixed cultures are more homogenous and, in both cases, an average recovery below $50 \%$ is achieved. Alcohol extraction seems to be more efficient for MMC than for single strains (recovery of $83 \%$ vs. $75 \%$ ), however, the result is not robust as there is just one study about the extraction of MMC with this kind of solvents that cannot be considered as a real benchmark (the same holds true for ketones applied to MMC, Werker et al., 2015).

The recovery of PHA from both single strains and MMC by applying a cellular lysis approach (Figure 5) is higher 


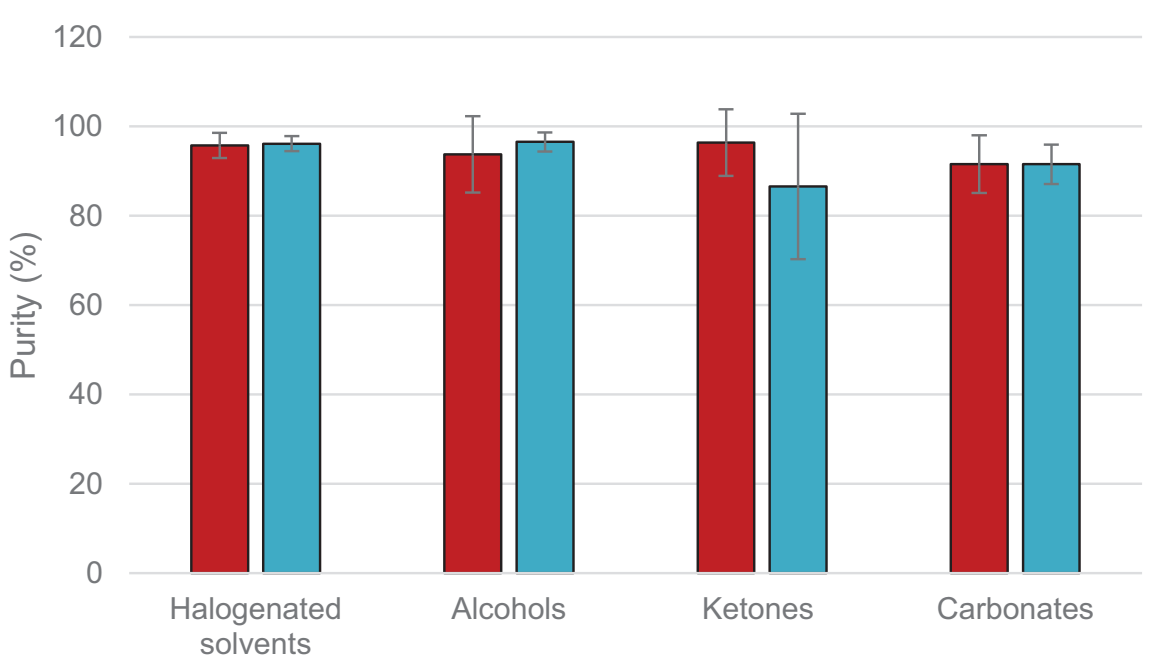

口Single strains $\square \mathrm{MMC}$

FIGURE 8| Mean PHA purity (\%) achieved through extraction with solvents (halogenated solvents, alcohols, ketones, and carbonates) from single strains or MMC.

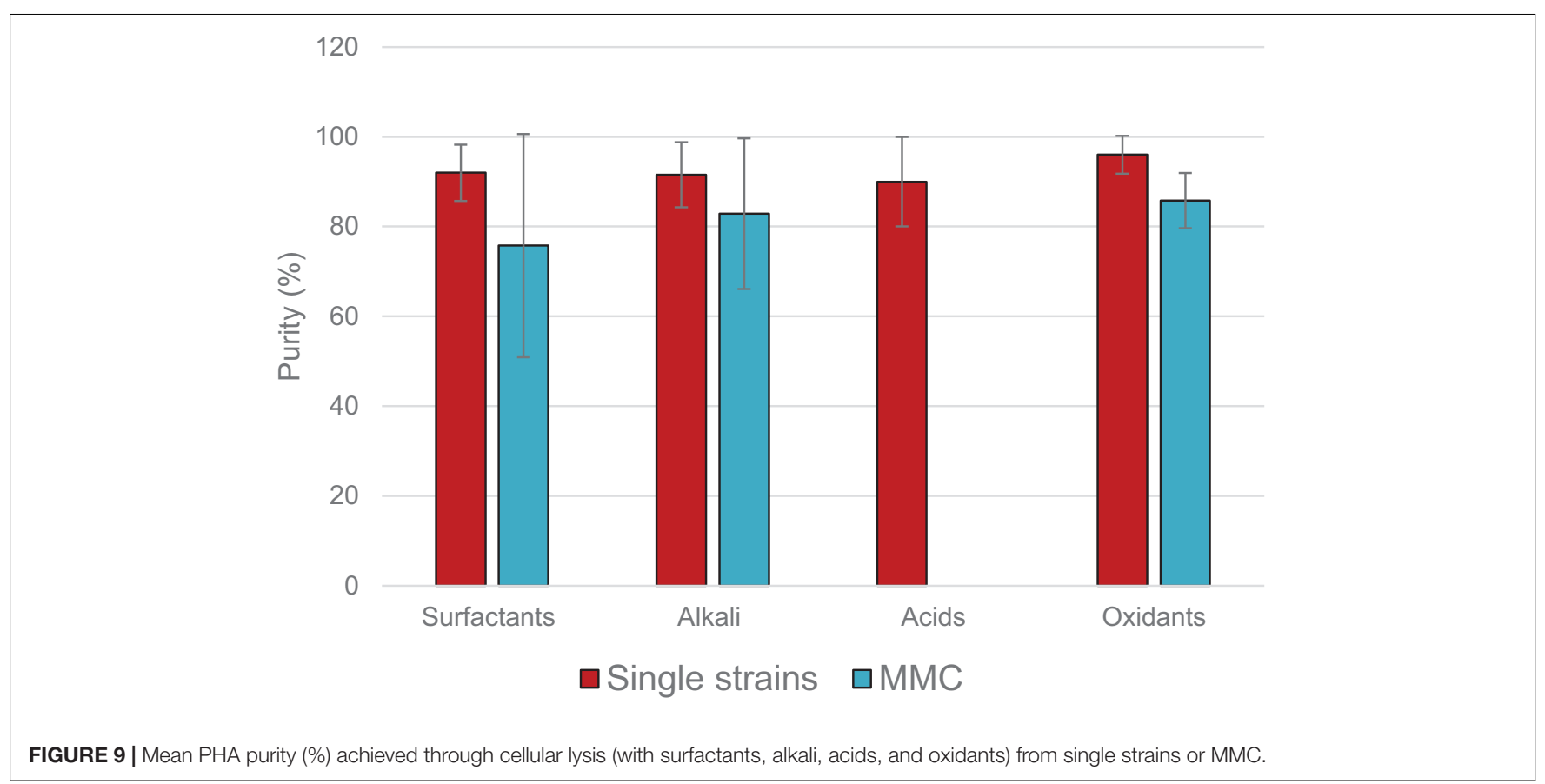

than what achievable by applying a solvent extraction; the average recoveries with surfactants, alkali, acids or oxidants are typically above $80 \%$, whereas few solvents perform better than this threshold (Figure 4). The major differences between single strains and MMC are observed when cellular lysis is performed with surfactants (Figure 5), being the average recovery of PHA of 89 and 75\%, respectively, whereas both the treatments with alkali and $\mathrm{NaClO}$ provide very similar results. By considering just the recovery percentage, surfactants, alkali, acids and oxidants perform well and similarly.
It is important to highlight that method that involve surfactants and alkali often include some pretreatments, especially with $\mathrm{NaClO}$ (Tables 2, 5) which has a strong oxidizing behavior capable of breaking cell membranes and enhancing the recovery.

\section{Molecular Weight}

The molecular weights of polymers extracted with halogenated solvents are the highest among the ones achievable from both single strains and MMCs, ranging between 0.8 and $0.9 \mathrm{MDa}$, even if a large variability of the literature results is observed (Figure 6). 
Carbonates behave similarly, especially on single strains, and even in this case, a large variability is observed. Both carbonates and halogenated solvents seem to not shorten the length of polymer chains by side reactions (e.g., transesterification), and, at the same time, seem to be the best solvents for solubilizing high molecular weight PHA; this confirms alkyl carbonates as an effective and environmentally alternative for PHA extraction instead of other solvents.

In the literature there are few reports about the molecular weight of polymers extracted with ketones and alcohols, especially for MMCs, therefore the results are not very robust. The average PHA's molecular weight extracted with ketones or alcohols from mixed and single strains is around 0.5 $\mathrm{MDa}$ but with high standard deviation in both cases (Figure 6); however, these lower values can be a confirmation of the suitability of ketones and alcohols for recovering "shorter" polymers than those extractable with carbonates and halogenated solvents.

The molecular weights of polymers extracted through cellular lysis (Figure 7) are largely variable. However, it seems quite clear that even if alkaline compounds do not compromise the length of PHA extracted from single strains (about 0.9 MDa), the same does not hold true for acids $(0.2 \mathrm{MDa})$, oxidants $(0.4 \mathrm{MDa})$ and surfactants $(0.6 \mathrm{MDa})$. If the results got with $\mathrm{NaClO}$ are not surprising given its oxidizing nature, surfactants action is more unexpected; however, many data used here for creating the average molecular weight data achieved with surfactants come from a cellular lysis process composed by a pre-treatment with $\mathrm{NaClO}$, followed by treatment with the surfactant itself. Another common pretreatment is a drying step prior to the polymer extraction (freeze-drying or thermal treatment); according to Koller et al. (2013), these pretreatments enhanced the polymer extraction causing the hydrolytic shortage of the polyester chains, more intrusive in the case of heat treatments than freeze-drying.

PHA recovered from MMC have much lower molecular weight averages than single strains, especially in the case of alkali and surfactants; this finding can be a confirmation of the higher resistance of MMC membranes than single strain membranes toward a "chemical" agent. Such resistance decreases when a strong oxidant is used, giving similar average molecular weights between single and mixed bacteria.

\section{Purity}

The purity level of PHA extracted with solvents is very high (above 90\%, Figure 8), independent by the type of solvent and the bacteria (single strains or MMC), the variability of this parameter is the lowest among those of all the parameters here used for comparing the extraction methods found in the literature (recovery and molecular weight). The PHA purity values obtained from cellular lysis approaches are lower, especially when MMCs are used (values below 90\% with all the chemicals used, Figure 9). Larger variabilities can be noticed with this approach in comparison to solvent-based protocols, especially for less harsh treatments like the ones with surfactants and alkaline compounds.

\section{CONCLUSION}

Considering the whole literature about PHA recovery from single strains and $\mathrm{MMC}$ it appears clear that a large variability of the results can be found. However, this variegate scenario strictly reflects the variability of bacteria, PHA initial content (that can influence the strength of the membranes), PHA type (homopolymers or co-polymers, and the ratio between short and long monomers), and recovery methods (temperature, pressure, need of pretreatments, concentrations of chemicals,...). Such variability is especially relevant for MMC, and this can be attributed to the variability of PHA content of MMC and the chemical features of MMCderived PHA.

A focus on two of the most crucial parameters (purity and molecular weight) that can influence the applicability of the recovered $\mathrm{PHA}$ reveals that the solvent extraction approach generally gives purity above $98 \%$, and molecular weight values above $0.8 \mathrm{MDa}$ in the case of halogenated solvents and carbonates; lower values are got with ketones and alcohols, reasonably for a lower affinity of these class of solvents for PHA and not for a real shortening-chain effect.

The cellular lysis approach provides higher recoveries than the solvent-based approach, mainly due to the definition of "extraction yields" within such procedure. Given that the "extraction yields" are defined as the amount of PHA that stays in the solid phase, the PHA losses during cellular lysis are mainly due to severe PHA degradation. It follows that the two issues that affect the cellular lysis approach are the PHA purity and quality (e.g., molecular weight and PDI), and both fall in a quite wide range independent of single strains or MMC. The lower average purity obtained in some studies presented in the literature (70$80 \%$ ) could be considered closer to a "refined microbial biomass" than "extracted PHA."

\section{AUTHOR CONTRIBUTIONS}

GP developed the whole manuscript preparing and integrating the different parts. PG participated in the manuscript design and revised the manuscript. CS conceived the study and contributed to write the chemical aspects of the work and revised the manuscript. AZ contributed to collect and study the references cited. CT contributed to write the aspects of efficiency issues of PHA extraction and revised the manuscript. All the authors read and approved the final manuscript.

\section{FUNDING}

The work was published with the contribution of the Department of Excellence program financed by the Ministry of Education, University and Research (MIUR, L. 232 del 01/12/2016). 


\section{REFERENCES}

Abbondanzi, F., Biscaro, G., Carvalho, G., Favaro, L., Lemos, P., Paglione, M., et al. (2017). Fast method for the determination of short-chain-length polyhydroxyalkanoates (scl-PHAs) in bacterial samples by In Vial-Thermolysis (IVT). New Biotechnol. 39, 29-35. doi: 10.1016/j.nbt.2017.05.012

Albuquerque, M. G. E., Martino, V., Pollet, E., Avérous, L., and Reis, M. A. M. (2011). Mixed culture polyhydroxyalkanoate (PHA) production from volatile fatty acid (VFA)-rich streams: Effect of substrate composition and feeding regime on PHA productivity, composition and properties. J. Biotechnol. 151, 66-76. doi: 10.1016/j.jbiotec.2010.10.070

Anis, S. N. S., Iqbal, N. M., Kumar, S., and Al-Ashraf, A. (2013a). Increased recovery and improved purity of PHA from recombinant Cupriavidus necator. Bioengineered 4, 115-118. doi: 10.4161/bioe.22350

Anis, S. N. S., Iqbal, N. M., Kumar, S., and Amirul, A. A. (2013b). Effect of different recovery strategies of $\mathrm{P}(3 \mathrm{HB}-\mathrm{co}-3 \mathrm{HHx})$ copolymer from Cupriavidus necator recombinant harboring the PHA synthase of Chromobacterium sp. USM2. Sep. Purif. Technol. 102, 111-117. doi: 10.1016/j.seppur.2012.09.036

Aoyagia, Y., Yamashita, K., and Doi, Y. (2002). Thermal degradation of poly[(R)3-hydroxybutyrate],poly[e-caprolactone], and poly[(S)-lactide]. Polym. Degrad. Stabil. 76, 53-59. doi: 10.1016/S0141-3910(01)00265-8

Aramvash, A., Gholami-Banadkuki, N., Moazzeni-Zavareh, F., and HajizadehTurchi, S. (2015). An environmentally friendly and efficient method for extraction of PHB biopolymer with non-halogenated solvents. J. Microbiol. Biotechn. 22, 1936-1943. doi: 10.4014/jmb.1505.05053

Aramvash, A., Moazzeni Zavareh, F., and Gholami Banadkuki, N. (2018). Comparison of different solvents for extraction of polyhydroxybutyrate from Cupriavidus necator. Eng. Life Sci. 18, 20-28. doi: 10.1002/elsc.201700102

Arcos-Hernández, M. V., Laycock, B., Donose, B. C., Pratt, S., Halley, P., AlLuaibi, S., et al. (2013). Physicochemical and mechanical properties of mixed culture polyhydroxyalkanoate (PHBV). Eur. Polym. J. 49, 904-913. doi: 10. 1016/j.eurpolymj.2012.10.025

Bengtsson, S., Pisco, A. R., Johansson, P., Lemos, P. C., and Reis, M. A. M. (2010). Molecular weight and thermal properties of polyhydroxyalkanoates produced from fermented sugar molasses by open mixed cultures. J. Biotechnol. 147, 172-179. doi: 10.1016/j.jbiotec.2010.03.022

Berger, E., Ramsay, B. A., Ramsay, J. A., Chavarie, C., and Braunegg, G. (1989). PHB recovery by hypochlorite digestion of non-PHB biomass. Biotechnology 3 , 227-232. doi: 10.1007/BF01876053

Braunegg, G., Sonnleitner, B., and Lafferty, R. M. (1978). A rapid gas chromatographic method for the determination of poly- $\beta$-hydroxybutyric acid in microbial biomass. Eur. J. Appl. Microbiol. Biot. 6, 29-37. doi: 10.1007/ BF00500854

Burniol-Figols, A., Skiadas, I. V., Daugaard, A. E., and Gavala, H. N. (2020). Polyhydroxyalkanoate (PHA) purification through dilute aqueous ammonia digestion at elevated temperatures. J. Chem. Technol. Biot. 95, 1519-1532. doi: $10.1002 / j \mathrm{ctb} .6345$

Cavalheiro, J. M. B. T., de Almeida, M. C. M. D., Grandfils, C., and da Fonseca, M. M. R. (2009). Poly(3-hydroxybutyrate) production by Cupriavidus necator using waste glycerol. Process Biochem. 44, 509-515. doi: 10.1016/j.procbio.2009. 01.008

Chan, C. M., Johansson, P., Magnusson, P., Vandi, L. J., Arcos-Hernandez, M., Halley, P., et al. (2017). Mixed culture polyhydroxyalkanoate-rich biomass assessment and quality control using thermogravimetric measurement methods. Polym. Degrad. Stabil. 144, 110-120. doi: 10.1016/j.polymdegradstab. 2017.07.029

Chen, G. Q., Zhang, G., Park, S. J., and Lee, S. Y. (2001). Industrial scale production of poly(3-hydroxybutyrate-co-3-hydroxyhexanoate). Appl. Microbiol. Biot. 57, 50-55. doi: 10.1007/s002530100755

Chen, Y., Chen, J., Yu, C., Du, G., and Lun, S. (1999). Recovery of poly-3hydroxybutyrate from Alcaligenes eutrophus by surfactant-chelate aqueous system. Process Biochem. 34, 153-157. doi: 10.1016/S0032-9592(98)00082-X

Choi, J., and Lee, S. Y. (1999). Efficient and economical recovery of poly(3hydroxybutyrate) from recombinant Escherichia coli by simple digestion with chemicals. Biotechnol. Bioeng. 62, 546-553. doi: 10.1002/(sici)10970290(19990305)62:5<546::aid-bit6>3.0.co;2-0
Dai, Y., Lambert, L., Yuan, Z., and Keller, J. (2008). Characterisation of polyhydroxyalkanoate copolymers with controllable four-monomer composition. J. Biotechnol. 134, 137-145. doi: 10.1016/j.jbiotec.2008.01.013

Dai, Y., Yuan, Z., Jack, K., and Keller, J. (2007). Production of targeted poly(3hydroxyalkanoates) copolymers by glycogen accumulating organisms using acetate as sole carbon source. J. Biotechnol. 129, 489-497. doi: 10.1016/j.jbiotec. 2007.01.036

De Castro, M. D., and Priego-Capote, L. (2010). Soxhlet extraction: past and present panacea. J. Chromatogr. A 1217, 2383-2389. doi: 10.1016/j.chroma. 2009.11.027

De Koning, G. J. M., and Witholt, B. (1997). A process for the recovery of poly(hydroxyalkanoates) from Pseudomonads Part 1: Solubilization. Bioprocess Eng. 17, 7-13. doi: 10.1007/s004490050345

Dias, J. M. L., Lemos, P. C., Serafim, L. S., Oliveira, C., Eiroa, M., Albuquerque, M. G. E., et al. (2006). Recent advances in polyhydroxyalkanoate production by mixed aerobic cultures: From the substrate to the final product. Macromol. Biosci. 6, 6885-6906. doi: 10.1002/mabi.200600112

Divyashree, M. S., Shamala, T. R., and Rastogi, N. K. (2009). Isolation of polyhydroxyalkanoate from hydrolyzed cells of Bacillus flexus using aqueous two-phase system containing polyethylene glycol and phosphate. Biotechnol. Bioproc. E 14, 482-489. doi: 10.1007/s12257-008-0119-z

Dobroth, Z. T., Hu, S., Coats, E. R., and McDonald, A. G. (2011). Polyhydroxybutyrate synthesis on biodiesel wastewater using mixed microbial consortia. Bioresource Technol. 102, 3352-3359. doi: 10.1016/j.biortech.2010. 11.053

Dong, Z., and Xuenan, S. (2000). A new method of recovering polyhydroxyalkanoate from Azotobacter chroococcum. Chinese Sci. Bull. 45, 252-256. doi: 10.1007/BF02884685

Dubey, S., Bharmoria, P., Gehlot, P. S., Agrawal, V., Kumar, A., and Mishra, S. (2018). 1-Ethyl-3-methylimidazolium Diethylphosphate based extraction of bioplastic "Polyhydroxyalkanoates" from bacteria: green and sustainable approach. ACS Sustain. Chem. Eng. 6, 766-773. doi: 10.1021/acssuschemeng. $7 \mathrm{~b} 03096$

Duque, A. F., Oliveira, C. S. S., Carmo, I. T. D., Gouveia, A. R., Pardelha, F., Ramos, A. M., et al. (2014). Response of a three-stage process for PHA production by mixed microbial cultures to feedstock shift: Impact on polymer composition. New Biotechnol. 31, 276-288. doi: 10.1016/j.nbt.2013.10.010

Elbahloul, Y., and Steinbüchel, A. (2009). Large-scale production of poly(3hydroxyoctanoic acid) by Pseudomonas putida GPo1 and a simplified downstream process. Appl. Environ. Microb. 75, 643-651. doi: 10.1128/AEM. 01869-08

EPA Environmental Protection Agency (EPA) (1990). List of Hazardous Air Pollutants. Available online at: https://www.epa.gov/haps/initial-listhazardous-air-pollutants-modifications (accessed 2020).

Fei, T., Cazeneuve, S., Wen, Z., Wu, L., and Wang, T. (2016). Effective recovery of poly- $\beta$-hydroxybutyrate (PHB) biopolymer from Cupriavidus necator using a novel and environmentally friendly solvent system. Biotechnol. Progr. 32, 678-685. doi: 10.1002/btpr.2247

FEMA (2009) Number 2178, JECFA Number 85, CAS 71-36-3, CFR 21CFR172.515, 21CFR172.560. Available online at: https://www.femaflavor. org/flavor-library/butyl-alcohol (accessed 2020).

Fernández-Dacosta, C., Posada, J. A., Kleerebezem, R., Cuellar, M. C., Ramirez, A. (2015). Microbial community-based polyhydroxyalkanoates (PHAs) production from wastewater: techno-economic analysis and ex-ante environmental assessment. Bioresource Technol. 185, 368-377. doi: 10.1016/j. biortech.2015.03.025

Fiorese, M. L., Freitas, F., Pais, J., Ramos, A. M., de Aragão, G. M. F., and Reis, M. A. M. (2009). Recovery of polyhydroxybutyrate (PHB) from Cupriavidus necator biomass by solvent extraction with 1,2-propylene carbonate. Eng. Life Sci. 9, 454-461. doi: 10.1002/elsc.200900034

Furrer, P., Panke, S., and Zinn, M. (2007). Efficient recovery of low endotoxin medium-chain-length poly([R]-3-hydroxyalkanoate) from bacterial biomass. J. Microbiol. Meth. 69, 206-213. doi: 10.1016/j.mimet.2007. 01.002

Gałuszka, A., Migaszewski, Z., and Namieśnik, J. (2013). The 12 principles of green analytical chemistry and the significance mnemonic of green analytical practices. Trac Trend Anal. Chem. 50, 78-84. doi: 10.1016/j.trac.2013.04.010 
Gorenflo, V., Schmack, G., Vogel, R., and Steinbüchel, A. (2001). Development of a process for the biotechnological large-scale production of 4-hydroxyvaleratecontaining polyesters and characterization of their physical and mechanical properties. Biomacromolecules 2, 45-57. doi: 10.1021/bm0000992

Gorenflo, V., Steinbüchel, A., Marose, S., Reiseberg, M., and Scheper, T. (1999). Quantification of bacterial polyhydroxyalkanoic acids by Nile red staining. Appl. Microbiol. Biot. 51, 765-772. doi: 10.1007/s002530051460

Grage, K., Jahns, A. C., Parlane, N., Palanisamy, R., Rasiah, I. A., Atwood, J. A., et al. (2009). Bacterial Polyhydroxyalkanoate granules: biogenesis, structure, and potential use as Nano-/micro-beads in biotechnological and biomedical applications. Biomacromolecules 10, 660-669. doi: 10.1021/bm801394s

Hahn, S. K., and Chang, Y. K. (1995). A themogravimetric analysis for poly(3hydroxybutyrate) quantification. Biotechnol. Tech. 9, 873-878. doi: 10.1007/ BF00158539

Hahn, S. K., Chang, Y. K., Kim, B. S., Lee, K. M., and Chang, H. N. (1993). The recovery of poly(3-hydroxybutyrate) by using dispersions of sodium hypochlorite solution and chloroform. Biotechnol. Tech. 7, 209-212. doi: 10. 1007/BF02566149

Hampson, J. W., and Ashby, R. D. (1999). Extraction of lipid-grown bacterial cells by supercritical fluid and organic solvent to obtain pure medium chain-length polyhydroxyalkanoates. JAOCS 76, 1371-1374. doi: 10.1007/s11746-999-0152$\mathrm{x}$

Heinrich, D., Madkour, M. H., Al-Ghamdi, M. A., Shabbaj, I. I., and Steinbüchel, A. (2012). Large scale extraction of poly(3-hydroxybutyrate) from Ralstonia eutropha H16 using sodium hypochlorite. AMB Express. 2:59. doi: 10.1186/ 2191-0855-2-59

Henderson, R. K., Jimenez-Gonzalez, C., Constable, D. J. C., Alston, S. R., Inglis, G. A. G., Fisher, G., et al. (2011). Expanding GSK's solvent selection guide embedding sustainability into solvent selection starting at medicinal chemistry. Green Chem. 13, 854-862. doi: 10.1039/c0gc00918k

Holmes, P. A., and Lim, G. B. (1990). Separation Process. US Patent No 4,910,145. Washington, DC: U.S. Patent and Trademark Office.

Hrabak, O. (1992). Industrial production of poly- $\beta$-hydroxybutyrate. FEMS Microbiol. Lett. 103, 251-255. doi: 10.1111/j.1574-6968.1992.tb05845.x

Hu, S., McDonald, A. G., and Coats, E. R. (2013). Characterization of polyhydroxybutyrate biosynthesized from crude glycerol waste using mixed microbial consortia. J. Appl. Polym. Sci. 129, 1314-1321. doi: 10.1002/app. 38820

International Agency for Research on Cancer (IARC) (1999). Monographs on the Identification of Carcinogenic Hazards to Humans. Available online at: https://publications.iarc.fr/Book-And-Report-Series/IarcMonographs-On-The-Identification-Of-Carcinogenic-Hazards-To-Humans (accessed 2020).

Irdahayu, N. M. N. M., Shantini, K., Huong, K. H., Vigneswari, S., Aziz, N. A., Azizan, M. N. M., et al. (2017). En route to economical eco-friendly solvent system in enhancing sustainable recovery of poly(3-hydroxybutyrate-co-4hydroxybutyrate) copolymer. Eng. Life Sci. 17, 1050-1059. doi: 10.1002/elsc. 201600217

Jacquel, N., Lo, C. W., Wei, Y. H., Wu, H. S., and Wang, S. S. (2008). Isolation and purification of bacterial poly(3-hydroxyalkanoates). Biochem. Eng. J. 39, 15-27. doi: 10.1016/j.bej.2007.11.029

Jendrossek, D. (2007). Peculiarities of PHA granules preparation and PHA depolymerase activity determination. Appl. Microbiol. Biot. 74, 1186-1196. doi: 10.1007/s00253-007-0860-9

Jendrossek, D. (2009). Polyhydroxyalkanoate granules are complex subcellular organelles (Carbonosomes). J. Bacteriol. 191, 3195-3202. doi: 10.1128/JB. 01723-08

Jendrossek, D., and Pfeiffer, D. (2014). New insights in the formation of polyhydroxyalkanoate granules (carbonosomes) and novel functions of poly(3hydroxybutyrate). Environ. Microbiol. 16, 2357-2373. doi: 10.1111/1462-2920. 12356

Jiang, G., Johnston, B., Townrow, D. E., Radecka, I., Koller, M., Chaber, P., et al. (2018). Biomass extraction using non-chlorinated solvents for biocompatibility improvement of polyhydroxyalkanoates. Polymers 10, 731-744. doi: 10.3390/ polym 10070731

Jiang, X., Ramsay, J. A., and Ramsay, B. A. (2006). Acetone extraction of mclPHA from Pseudomonas putida KT2440. J. Microbiol. Meth. 67, 212-219. doi: 10.1016/j.mimet.2006.03.015
Jiang, Y., Mikova, G., Kleerebezem, R., van der Wielen, L. A. M., and Cuellar, M. C. (2015). Feasibility study of an alkaline-based chemical treatment for the purification of polyhydroxybutyrate produced by a mixed enriched culture. AMB Express. 5, 5-13. doi: 10.1186/s13568-015-0096-5

Johnson, K., Jiang, Y., Kleerebezem, R., Muyzer, G., and van Loosdrecht, M. C. M. (2009). Enrichment of a mixed bacterial culture with a high polyhydroxyalkanoate storage capacity. Biomacromolecules 4, 670-676. doi: 10. $1021 / \mathrm{bm} 8013796$

Kachrimanidou, V., Kopsahelis, N., Vlysidis, A., Papanikolaou, S., Kookos, I. K., Monje Martínez, B., et al. (2016). Downstream separation of poly(hydroxyalkanoates) using crude enzyme consortia produced via solid state fermentation integrated in a biorefinery concept. Food Bioprod. Process 100, 323-334. doi: 10.1016/j.fbp.2016.08.002

Kapritchkoff, F. M., Viotti, A. P., Alli, R. C. P., Zuccolo, M., Pradella, J. G. C., Maiorano, A. E., et al. (2006). Enzymatic recovery and purification of polyhydroxybutyrate produced by Ralstonia eutropha. J. Biotechnol. 122, 453462. doi: 10.1016/j.jbiotec.2005.09.009

Kathiraser, Y., Arouam, M. K., Ramachandran, K. B., and Tan, I. K. P. (2007). Chemical characterization of medium-chain-length polyhydroxyalkanoates (PHAs) recovered by enzymatic treatment and ultrafiltration. J. Chem. Technol. Biot. 82, 847-855. doi: 10.1002/jctb.1751

Kemper, T. G. (1997). "Solvent recovery and loss management," in Technology and Solvents for Extracting Oilseeds and Nonpetroleum Oils, eds P. J. Wan and P. J. Wakelyn (Champaign, IL: AOCS), 148-152.

Kim, M., Cho, K. S., Ryu, H. W., Lee, E. G., and Chang, Y. K. (2003). Recovery of poly(3-hydroxybutyrate) from high cell density culture of Ralstonia eutropha by direct addition of sodium dodecyl sulfate. Biotechnol. Lett. 25, 55-59. doi: 10.1023/A:1021734216612

Kobayashi, D., Fujita, K., Nakamura, N., and Ohno, H. (2015). A simple recovery process for biodegradable plastics accumulated in cyanobacteria treated with ionic liquids. Appl. Microbiol. Biot. 99, 1647-1653. doi: 10.1007/s00253-0146234- 1

Koller, M. (2020). Established and advanced approaches for recovery of microbial polyhydroxyalkanoate (PHA) biopolyesters from surrounding microbial biomass. Bioprocess Eng. 4, 113-126. doi: 10.2478/ebtj-2020-0013

Koller, M., Maršálek, L., de Sousa Dias, M. M., and Braunegg, G. (2017). Producing microbial polyhydroxyalkanoate (PHA) biopolyesters in a sustainable manner. New Biotechnol. 37, 24-38. doi: 10.1016/j.nbt.2016.05.001

Koller, M., Niebelschütz, H., and Braunegg, G. (2013). Strategies for recovery and purification of poly[(R)-3-hydroxyalkanoates] (PHA) biopolyesters from surrounding biomass. Eng. Life Sci. 13, 549-562. doi: 10.1002/elsc.201300021

Kosseva, M. R., and Rusbandi, E. (2018). Trends in the biomanufacture of polyhydroxyalkanoates with focus on downstream processing. Int. J. Biol. Macromol. 107, 762-778. doi: 10.1016/j.ijbiomac.2017.09.054

Kuchta, K., Chi, L., Fuchs, H., Pötter, M., and Steinbüchel, A. (2007). Studies on the influence of phasins on accumulation and degradation of PHB and nanostructure of PHB granules in Ralstonia eutropha H16. Biomacromolecules 8, 657-662. doi: 10.1021/bm060912e

Kunasundari, B., Murugaiyah, V., Kaur, G., Maurer, F. H., and Sudesh, K. (2013). Revisiting the single cell protein application of Cupriavidus necator H16 and recovering bioplastic granules simultaneously. PLoS One 8:e78528. doi: 10. 1371/journal.pone.0078528

Kunasundari, B., and Sudesh, K. (2011). Isolation and recovery of microbial polyhydroxyalkanoates. Express Polym. Lett. 5, 620-634. doi: 10.3144/ expresspolymlett. 2011.60

Lakshman, K., and Shamala, T. R. (2006). Extraction of polyhydroxyalkanoate from Sinorhizobium meliloti cells using Microbispora sp. culture and its enzymes. Enzyme Microb. Tech. 39, 1471-1475. doi: 10.1016/j.enzmictec.2006.03.037

Laycock, B., Arcos-Hernandez, M. V., Langford, A., Pratt, S., Werker, A., Halley, P. J., et al. (2014). Crystallisation and fractionation of selected polyhydroxyalkanoates produced from mixed cultures. New Biotechnol. 31, 345-356. doi: 10.1016/j.nbt.2013.05.005

Lee, K. M., Chang, H. N., Chang, Y. K., Kim, S., and Hahn, S. K. (1993). The lysis of gram-negative Alcaligenes Euthophus and Alcaligenes latus by palmitoyl carnitine. Biotechnol. Tech. 7, 295-300. doi: 10.1007/BF00150902

Lee, S. Y., Choi, J., Han, K., and Song, J. Y. (1999). Removal of endotoxin during purification of Poly(3-Hydroxybutyrate) from gram-negative bacteria. Appl. Environ. Microbiol. 65, 2762-2764. doi: 10.1128/AEM.65.6.2762-2764.1999 
Lemos, P. C., Viana, C., Salgueiro, E. N., Ramos, A. M., Crespo, J. P. S. G., and Reis, M. A. M. (1998). Effect of carbon source on the formation of polyhydroxyalkanoates (PHA) by a phosphate-accumulating mixed culture. Enzyme Microb. Tech. 22, 662-671. doi: 10.1016/S0141-0229(97)00243-3

Li, L., Han, J., Wang, Z., Liu, J., Wei, J., Xiong, S., et al. (2014). Mass spectrometry methodology in lipid analysis. Int. J. Mol. Sci. 15, 10492-10507. doi: 10.3390/ ijms150610492

Li, S. D., He, J. D., Yu, P. H., and Cheung, M. K. (2003). Thermal degradation of poly(3-hydroxybutyrate) and poly(3-hydroxybutyrate-co-3-hydroxyvalerate) as studied by TG, TG-FTIR, and Py-GC/MS. J. Appl. Polym. Sci. 89, 1530-1536. doi: 10.1002/app.12249

López-Abelairas, M., García-Torreiro, M., Lú-Chau, T., Lema, J. M., and Steinbüchel, A. (2015). Comparison of several methods for the separation of poly(3-hydroxybutyrate) from Cupriavidus necator $\mathrm{H} 16$ cultures. Biochem. Eng. J. 93, 250-259. doi: 10.1016/j.bej.2014.10.018

Lorini, L., Martinelli, A., Pavan, P., Majone, M., and Valentino, F. (2020). Downstream processing and characterization of polyhydroxyalkanoates (PHAs) produced by mixed microbial culture (MMC) and organic urban waste as substrate. Biomass Conv. Bioref. doi: 10.1007/s13399-020-00788-w

Lowry, O. H., Rosebrough, N. J., Farr, A. L., and Randall, R. J. (1951). Protein measurement with the Folin phenol reagent. J. Biol. Chem. 193, 265-275. doi: 10.1016/s0021-9258(19)52451-6

Lupescu, I., Eremia, M. C., Savoiu, G. V., Spiridoni, M., and Panaitescu, D. (2016). Comparative studies on isolation of medium-chain-length Polyhydroxyalkanoates produced by Pseudomonas spp. Strains. Rev. Chim. 67, 1957-1962.

Madkour, M. H., Heinrich, D., Alghamdi, M. A., Shabbaj, I. I., and Steinbüchel, A. (2013). PHA recovery from biomass. Biomacromolecules 14, 2963-2972. doi: $10.1021 / \mathrm{bm} 4010244$

Manangan, T., and Shawaphun, S. (2010). Quantitative extraction and determination of polyhydroxyalkanoate accumulated in Alcaligenes latus dry cells. Science 36, 199-203. doi: 10.2306/scienceasia1513-1874.2010.36.199

Mannina, G., Presti, D., Montiel-Jarillo, G., Carrera, J., and Suárez-Ojeda, M. E. (2020). Recovery of polyhydroxyalkanoates (PHAs) from wastewater: a review. Bioresource Technol. 297:122478. doi: 10.1016/j.biortech.2019.122478

Mannina, G., Presti, D., Montiel-Jarillo, G., and Suárez-Ojeda, M. E. (2019). Bioplastic recovery from wastewater: a new protocol for polyhydroxyalkanoates (PHA) extraction from mixed microbial cultures. Bioresource Technol. 282, 361-369. doi: 10.1016/j.biortech.2019.03.037

Martínez, V., García, P., García, J. L., and Prieto, M. A. (2011). Controlled autolysis facilitates the polyhydroxyalkanoate recovery in Pseudomonas putida KT2440. Microb. Biotechnol. 4, 533-547. doi: 10.1111/j.1751-7915.2011.00257.x

Martínez, V., Herencias, C., Jurkevitch, E., and Prieto, M. A. (2016). Engineering a predatory bacterium as a proficient killer agent for intracellular bioproducts recovery: The case of the polyhydroxyalkanoates. Sci. Rep. 6:24381. doi: 10 . 1038/srep24381

Mayer, F., and Hoppert, M. (1997). Determination of the thickness of the boundary layer surrounding bacterial PHA inclusion bodies, and implications for models describing the molecular architecture of this layer. J. Basic Microb. 37, 45-52. doi: 10.1002/jobm.3620370108

McChalicher, C. W. J., Srienc, F., and Rouse, D. P. (2010). Solubility and degradation of polyhydroxyalkanoate biopolymers in propylene carbonate. AIChE J. 56, 1616-1625. doi: 10.1002/aic.12087

Merrick, J. M., and Doudoroff, M. (1964). Depolymerization of poly-betahydroxybutyrate by an intracellular enzyme system. J. Bacteriol. 88, 60-71. doi: 10.1128/jb.88.1.60-71.1964

Mohammadi, M., Hassan, M. A., Phang, L. Y., Ariffin, H., Shirai, Y., and Ando, Y. (2012a). Recovery and purification of intracellular polyhydroxyalkanoates from recombinant Cupriavidus necator using water and ethanol. Biotechnol. Lett. 34, 253-259. doi: 10.1007/s10529-011-0783-5

Mohammadi, M., Hassan, M. A., Phang, L. Y., Shirai, Y., Man, H. C., and Ariffin, H. (2012b). Intracellular polyhydroxyalkanoates recovery by cleaner halogen-free methods towards zero emission in the palm oil mill. J. Clean. Prod. 37, 353-560. doi: 10.1016/j.jclepro.2012.07.038

Morgan-Sagastume, F., Karlsson, A., Johansson, P., Pratt, S., Boon, N., Lant, P., et al. (2010). Production of polyhydroxyalkanoates in open, mixed cultures from a waste sludge stream containing high levels of soluble organics, nitrogen and phosphorus. Water Res. 44, 5196-5211. doi: 10.1016/j.watres.2010.06.043
Morikawa, H., and Marchessault, R. (1981). Pyrolysis of bacterial polyalkanoates. Can. J. Chem. 59, 2306-2313. doi: 10.1139/v81-334

Mothes, G., Schnorpfeil, C., and Ackermann, J. U. (2007). Production of PHB from crude glycerol. Eng. Life Sc. 7, 475-479. doi: 10.1002/elsc.200620210

Murugan, P., Han, L., Gan, C. Y., Maurer, F. H., and Sudesh, K. (2016). A new biological recovery approach for PHA using mealworm, Tenebrio molitor. J. Biotechnol. 239, 98-105. doi: 10.1016/j.jbiotec.2016.10.012

Neves, A., and Müller, J. (2012). Use of enzymes in extraction of polyhydroxyalkanoates produced by Cupriavidus necator. Biotechnol. Progr. 26, 1575-1580. doi: 10.1002/btpr.1624

Newman, S. G., and Jensen, K. F. (2013). The role of flow in green chemistry and engineering. Green Chem. 15, 1456-1472. doi: 10.1039/C3GC40374B

Nonato, R. V., Mantelatto, P. E., and Rossell, C. E. V. (2001). Integrated production of biodegradable plastic, sugar and ethanol. Appl. Microbiol. Biot. 57, 1-5. doi: $10.1007 / \mathrm{s} 002530100732$

Ong, S. Y., Zainab, L. I., Pyary, S., and Sudesh, K. (2018). A novel biological recovery approach for PHA employing selective digestion of bacterial biomass in animals. Appl. Microbiol. Biot. 122, 2117-2127. doi: 10.1007/s00253-0188788-9

Pagliano, G., Ventorino, V., Panico, A., and Pepe, O. (2017). Integrated systems for biopolymers and bioenergy production from organic waste and by-products: a review of microbial processes. Biotechnol. Biofuels 10, 113-137. doi: 10.1186/ s13068-017-0802-4

Patel, M., Gapes, D. J., Newman, R. H., and Dare, P. H. (2009). Physico-chemical properties of polyhydroxyalkanoate produced by mixed-culture nitrogen-fixing bacteria. Appl. Microbiol. Biot. 82, 545-555. doi: 10.1007/s00253-008-1836-0

Pérez-Rivero, C., López-Gómez, J. P., and Roy, I. (2019). A sustainable approach for the downstream processing of bacterial polyhydroxyalkanoates: state-of-the-art and latest developments. Biochem. Eng. J. 150, 108253. doi: 10.1016/j.bej.2019. 107283

Prat, D., Hayler, J., and Wells, A. (2014). A survey of solvent selection guides. Green Chem. 16, 4546-4551. doi: 10.1039/c4gc01149j

Prat, D., Wells, A., Hayler, J., Sneddon, H., McElroy, C. R., Abou-Shehadad, S., et al. (2016). CHEM21 selection guide of classical- and less classical-solvents. Green Chem. 18, 288-296. doi: 10.1039/c5gc01008j

Prati, S., Sciutto, G., Volpi, F., Rehorn, C., Vurro, R., Blumich, B., et al. (2019). Cleaning oil paintings: NMR relaxometry and SPME to evaluate the effects of green solvents and innovative green gels. New J. Chem. 43, 8229-8238. doi: 10.1039/c9nj00186g

Ramsay, J. A., Berger, E., Ramsay, B. A., and Chavarie, C. (1990). Recovery of poly-3-hydroxyalpoic acid granules by a surfactant hypochlorite treatment. Biotechnol. Tech. 4, 221-226. doi: 10.1007/BF00158833

Ramsay, J. A., Berger, E., Voyer, R., Chavarie, C., and Ramsay, B. A. (1994). Extraction of poly-3-hydroxybutyrate using chlorinated solvents. Biotechnol. Tech. 8, 589-594. doi: 10.1007/BF00152152

Reddy, C., Ghai, R., and Kalia, V. (2003). Polyhydroxyalkanoates: an overview. Bioresource Technol. 87, 137-146. doi: 10.1016/S0960-8524(02)0 0212-2

Reis, M. A. M., Serafim, L. S., Lemos, P. C., Ramos, A. M., Aguiar, F. R., and van Loosdrecht, M. C. M. (2003). Production of polyhydroxyalkanoates by mixed microbial cultures. Bioproc. Biosyst. Eng. 25, 377-385. doi: 10.1007/s00449-0030322-4

Riedel, S. L., Brigham, C. J., Budde, C. F., Bader, J., Rha, C., Stahl, U., et al. (2013). Recovery of poly(3-hydroxybutyrate-co-3-hydroxyhexanoate) from Ralstonia eutropha cultures with non-halogenated solvents. Biotechnol. Bioeng. 110, 461470. doi: 10.1002/bit.24713

Righi, S., Baioli, F., Samorì, C., Galletti, P., Tagliavini, E., Stramigioli, C., et al. (2017). A life cycle assessment of poly-hydroxybutyrate extraction from microbial biomass using dimethyl carbonate. J. Clean. Prod. 168, 692-707. doi: 10.1016/j.jclepro.2017.08.227

Rosengart, A., Cesário, M. T., de Almeida, M. C. M. D., Raposo, R. S., Espert, A., de Apodaca, E. D., et al. (2015). Efficient P(3HB) extraction from Burkholderia sacchari cells using non-chlorinated solvents. Biochem. Eng. J. 103, 39-46. doi: 10.1016/j.bej.2015.06.013

Ryu, H. W., Cho, K. S., Lee, E. G., and Chang, Y. K. (2000). Recovery of poly(3-hydroxybutyrate) from coagulated Ralstonia eutropha using a chemical digestion method. Biotechnol. Progr. 16, 676-679. doi: 10.1021/bp00 $0054 \mathrm{c}$ 
Saavedra del Oso, M., Mauricio-Iglesias, M., and Hospido, A. (2020). Evaluation and optimization of the environmental performance of PHA downstream processing. Chem. Eng. J. 2020:127687. doi: 10.1016/j.cej.2020.127687

Samorì, C., Abbondanzi, F., Galletti, P., Giorgini, L., Mazzocchetti, L., Torri, C., et al. (2015a). Extraction of polyhydroxyalkanoates from mixed microbial cultures: Impact on polymer quality and recovery. Bioresource Technol. 189, 195-202. doi: 10.1016/j.biortech.2015.03.062

Samorì, C., Basaglia, M., Casella, S., Favaro, L., Galletti, P., Giorgini, L., et al. (2015b). Dimethyl carbonate and switchable anionic surfactants: two effective tools for the extraction of polyhydroxyalkanoates from microbial biomass. Green Chem. 17, 1047-1056. doi: 10.1039/C4GC01821D

Samorì, C., Galletti, P., Giorgini, L., Mazzeo, R., Mazzocchetti, L., Prati, S., et al. (2016). The green attitude in art conservation: Polyhydroxybutyrate-based gels for the cleaning of oil paintings. Chemistry Select 1, 4502-4508. doi: 10.1002/ slct. 201601180

Serafim, L. S., Lemos, P. C., Albuquerque, M. G. E., and Reis, M. A. M. (2008a). Strategies for PHA production by mixed cultures and renewable waste materials. Appl. Microbiol. Biot. 81, 615-628. doi: 10.1007/s00253-008-1757-y

Serafim, L. S., Lemos, P. C., Torres, C., Reis, M. A. M., and Ramos, A. M. (2008b). The influence of process parameters on the characteristics of polyhydroxyalkanoates produced by mixed cultures. Macromol. Biosci. 8, 355366. doi: 10.1002/mabi.200700200

Sosulski, F. W., and Imafidon, G. I. (1990). Amino acid composition and nitrogento-protein conversion factors for animal and plant foods. J. Agric. Food Chem. 38, 1351-1356. doi: 10.1021/jf00096a011

Strazzullo, G., Gambacorta, A., Vella, F. M., Immirzi, B., Romano, I., Calandrelli, V., et al. (2008). Chemical-physical characterization of polyhydroxyalkanoates recovered by means of a simplified method from cultures of Halomonas campaniensis. World J. Microb. Biot. 24, 1513-1519. doi: 10.1007/s11274-0079637-7

Suk Roh, K., Ho Yeom, S., and Je Yoo, Y. (1995). The effects of sodium bisulfite in extraction of PHB by hypochlorite. he effects of sodium bisulfite in extraction of PHB by hypochlorite. Biotechnol. Tech. 9, 709-712. doi: 10.1007/BF00159234

Suzuki, D. V., Carter, J. M., Rodrigues, M. F. A., da Silva, E. S., and Maiorano, A. E. (2008). Purification of polyhydroxybutyrate produced by Burkholderia cepacia IPT64 through a chemical and enzymatic route. World J. Microb. Biot. 24, 771-775. doi: 10.1007/s11274-007-9537-x

Torri, C., Cordiani, H., Samorì, C., Favaro, L., and Fabbri, D. (2014). Fast procedure for the analysis of poly(hydroxyalkanoates) in bacterial cells by off-line pyrolysis/gas-chromatography with flame ionization detector. J. Chromatogr. A 1359, 230-236. doi: 10.1016/j.chroma.2014.07.008

Valappil, S. P., Misra, S. K., Boccaccini, A. R., Keshavarz, T., Bucke, C., and Roy, I. (2007). Large-scale production and efficient recovery of PHB with desirable material properties, from the newly characterised Bacillus cereus SPV. J. Biotechnol. 132, 251-258. doi: 10.1016/j.jbiotec.2007.03.013

Valentino, F., Morgan-Sagastume, F., Campanari, S., Villano, M., Werker, A., and Majone, M. (2017). Carbon recovery from wastewater through bioconversion into biodegradable polymers. New Biotechnol. 37, 9-23. doi: 10.1016/j.nbt.2016. 05.007

Villano, M., Valentino, F., Barbetta, A., Martino, L., Scandola, M., and Majone, M. (2014). Polyhydroxyalkanoates production with mixed microbial cultures: from culture selection to polymer recovery in a high-rate continuous process. New Biotechnol. 31, 289-296. doi: 10.1016/j.nbt.2013.08.001

Vogli, L., Macrelli, S., Marazza, D., Galletti, P., Torri, C., Samorì, C., et al. (2020). Life cycle assessment and energy balance of a novel polyhydroxyalkanoates production process with mixed microbial cultures fed on pyrolytic products of wastewater treatment sludge. Energies 13:2706. doi: 10.3390/en131 12706

Wampfler, B., Ramsauer, T., Kehl, K., Zinn, M., and Thony-Meyer, L. (2010a). Application of activated charcoal in the downstream processing of bacterial Olefinic Poly(3-hydroxyalkanoates). Chimia 64, 784-788. doi: 10.2533/chimia. 2010.784

Wampfler, B., Ramsauer, T., Rezzonico, S., Hischier, R., Köhling, R., ThönyMeyer, L., et al. (2010b). Isolation and purification of medium chain length poly(3-hydroxyalkanoates) (mcl-PHA) for medical applications using nonchlorinated solvents. Biomacromolecules 11, 2716-2723. doi: 10.1021/bm10 07663

Ward, A. C., and Dawes, E. A. (1973). A disk assay for poly- $\beta$-hydroxybutyrate. Anal. Biochem. 52, 607-613. doi: 10.1016/0003-2697(73)90067-5

Werker, A., Johansson, P., and Magnusson, P. (2015). Process for the Extraction of Polyhydroxyalkanoates from Biomass. U.S. Patent No 20150368393A1. France: VEOLIA Water Solutions \& Technologies.

Williams, D. R., Anderson, A. J., Dawes, E. A., and Ewing, D. F. (1994). Production of a co-polyester of 3-hydroxybutyric acid and 3-hydroxyvaleric acid from succinic acid by Rhodococcus ruber: biosynthetic considerations. Appl. Microbiol. Biot. 40, 717-723. doi: 10.1007/BF00173334

Williamson, D. H., and Wilkinson, J. F. (1958). The isolation and estimation of the poly-beta-hydroxybutyrate inclusions of Bacillus species. J. Gen. Microbiol. 19, 198-209. doi: 10.1099/00221287-19-1-198

Yang, Y. H., Brigham, C., Willis, L., Rha, C. K., and Sinskey, A. (2011). Improved detergent-based recovery of polyhydroxyalkanoates (PHAs). Biotechnol. Lett. 33, 937-942. doi: 10.1007/s10529-010-0513-4

Yang, Y. H., Jeon, J. M., Yi, D. H., Kim, J. H., Seo, H. M., and Rha, C. K. (2015). Application of a non-halogenated solvent, methyl ethyl ketone (MEK) for recovery of poly(3-hydroxybutyrate-co-3-hydroxyvalerate) [P(HB-co-HV)] from bacterial cells. Biotechnol. Bioproc. E 20, 291-297. doi: 10.1007/s12257014-0546-y

Yasotha, K., Aroua, M. K., Ramachandran, K. B., and Tan, I. K. P. (2006). Recovery of medium-chain-length polyhydroxyalkanoates (PHAs) through enzymatic digestion treatments and ultrafiltration. Biochem. Eng. J. 30, 260-268. doi: 10. 1016/j.bej.2006.05.008

Yu, J., and Chen, L. X. L. (2006). Cost-effective recovery and purification of polyhydroxyalkanoates by selective dissolution of cell mass. Biotechnol. Progr. 22, 547-553. doi: 10.1021/bp050362g

Zinn, M., Weilenmann, H. U., Hany, R., Schmid, M., and Egli, T. (2003). Tailored synthesis of poly([R]-3-hydroxybutyrate-co-3-hydroxyvalerate) $(\mathrm{PHB} / \mathrm{HV})$ in Ralstonia eutropha DSM 428. Acta Biotechnol. 23, 309-316. doi: 10.1002/abio. 200390039

Conflict of Interest: The authors declare that the research was conducted in the absence of any commercial or financial relationships that could be construed as a potential conflict of interest.

Copyright (c) 2021 Pagliano, Galletti, Samori, Zaghini and Torri. This is an openaccess article distributed under the terms of the Creative Commons Attribution License (CC BY). The use, distribution or reproduction in other forums is permitted, provided the original author(s) and the copyright owner(s) are credited and that the original publication in this journal is cited, in accordance with accepted academic practice. No use, distribution or reproduction is permitted which does not comply with these terms. 